\title{
Asthma: 2015 and Beyond
}

\author{
Timothy R Myers RRT-NPS and Liza Tomasio RRT-NPS
}

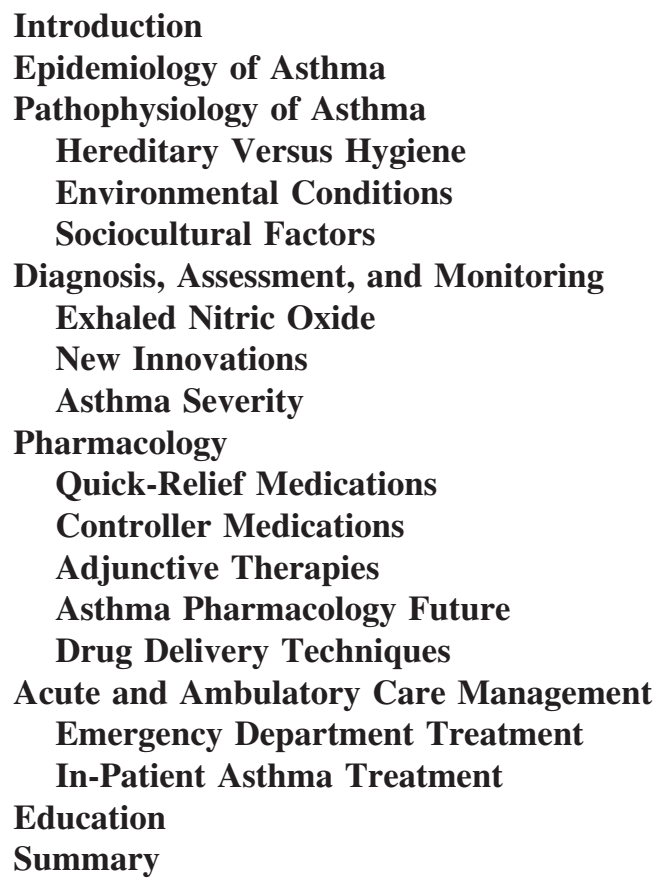

Asthma is a multifactorial, chronic inflammatory disease of the airways. The knowledge that asthma is an inflammatory disorder has become a core fundamental in the definition of asthma. Asthma's chief features include a variable degree of air-flow obstruction and bronchial hyper-responsiveness, in addition to the underlying chronic airways inflammation. This underlying chronic airway inflammation substantially contributes to airway hyper-responsiveness, air-flow limitation, respiratory symptoms, and disease chronicity. However, this underlying chronic airway inflammation has implications for the diagnosis, management, and potential prevention of the disease. This review for the respiratory therapy community summarizes these developments as well as providing an update on asthma epidemiology, natural history, cause, and pathogenesis. This paper also provides an overview on appropriate diagnostic and monitoring strategies for asthma, pharmacology, and newer therapies for the future as well as relevant management of acute and ambulatory asthma, and a brief review of educational approaches. Key words: pediatric; asthma; pediatric asthma; epidemiology; pathology; diagnosis; pharmacology; patient education. [Respir Care 2011;56(9):1389-1407. (C) 2011 Daedalus Enterprises]

Mr Myers and Ms Tomasio are affiliated with Pediatric Diagnostics and Respiratory Care, Rainbow Babies and Children's Hospital, Cleveland, Ohio.

Mr Myers presented a version of this paper at the 47th RESPIRATORY CARE Journal Conference, "Neonatal and Pediatric Respiratory Care: What Does the Future Hold?" held November 5-7, 2010, in Scottsdale, Arizona.
The authors have disclosed no conflicts of interest.

Correspondence: Timothy R Myers RRT-NPS, Pediatric Diagnostics and Respiratory Care, Rainbow Babies and Children's Hospital, $11100 \mathrm{Eu}-$ clid Avenue, Mailstop 6043, Cleveland OH 44106. E-mail: timothy. myers@uhhospitals.org.

DOI: $10.4187 /$ respcare. 01334 


\section{Introduction}

Asthma is a multifactorial, chronic inflammatory disease of the airways. The knowledge that asthma is an inflammatory disorder has become a core fundamental in the definition of asthma. Asthma's chief features include a variable degree of air-flow obstruction and bronchial hyper-responsiveness, in addition to the underlying chronic airways inflammation. This underlying chronic airway inflammation substantially contributes to airway hyper-responsiveness, air-flow limitation, respiratory symptoms, and disease chronicity. However, this underlying chronic airway inflammation has implications for the diagnosis, management, and potential prevention of the disease.

The diagnosis, management, and treatment of asthma have timelines that date back to antiquity. The Papyrus Ebers is an Egyptian medical papyrus dating to circa 1550 BC. Among the oldest and most important medical papyri of ancient Egypt, it contains hieroglyphic prescriptions that propose a remedy for asthma of "fumes from herbs heated on bricks to be inhaled by those suffering breathing maladies." Despite advances in research over the many centuries since these ancient writings, the management and treatment of asthma still contains many great mysteries and dozens of patient-specific nuances.

While incremental increases in morbidity and mortality in the 1980s characterized asthma in the United States, these trends peaked and more importantly plateaued in the 1990s, with asthma mortality rates steadily decreasing in the 21 st century. Over the past 30-40 years, asthma prevalence has increased in epidemic-like proportions within the United States and other industrialized countries; however, recent statistics may suggest a plateau has been reached in prevalence as well. Remarkable advancements have been attained in our primary comprehension of asthma pathogenesis, made possible through a multitude of invasive and noninvasive research and clinical tools, although the etiology and basis of airway inflammation today still remain somewhat obscure.

Over the past 20 years, the distribution and implementation of evidence-based guidelines for asthma have placed an increased scrutiny on the systematic use of anti-inflammatory therapy to improve asthma outcomes. With the increased knowledge of asthma's chronicity and the role of inflammation, a greater focus has been placed on early diagnosis and daily, maintenance strategies of children with asthma, in parallel with confirming adherence to prescribed therapies. Along with increased comprehension of acute and chronic asthma management have come advances in our pharmacologic armamentarium with the development and approval of novel medications.

This review of pediatric asthma for the respiratory therapy community attempts to summarize recent developments as well as those possibilities on the short-term ho- rizon. An update on asthma's epidemiology, natural history, etiology, and pathogenesis is included. This paper will provide a brief overview on appropriate diagnostic and monitoring strategies for asthma, pharmacology and newer therapies for the future, relevant management of acute and ambulatory asthma, and a brief review of educational approaches.

\section{Epidemiology of Asthma}

One of the major keys in discussing epidemiology of any disease begins and ends with a critical need for reliable surveillance instruments that can accurately track incidence and prevalence and classify population-level and geographic distributions or escalations in morbidity in a prospective time frame. Lurie et al intimate the requirement that "data need to be collected and evaluated not only on a national scale but also for individual states and communities, because many of the factors that are related to asthma outcomes can be influenced by local action". ${ }^{1}$

While no small task or endeavor, over the past several decades, several government agencies have been charged with surveillance for asthma, including the National Heart Lung Blood Institute's National Asthma Education and Prevention Program, the Department of Health and Human Services (Healthy People 2010), and the Centers for Disease Control and Prevention. While the Centers for Disease Control and Prevention has received funding to address the surveillance of asthma, ${ }^{2}$ substantial additional funding is necessary to develop a comprehensive public health approach that can consistently achieve positive effects. Mannino and colleagues identified one of the many flaws in the current system: the substantial time lag in the data release makes it difficult for communities that have implemented important policies to know whether their policies are effective and whether changes in the healthcare environment are having a positive impact. ${ }^{3}$

Currently there are no national mechanisms in place to measure the incidence (rate at which new cases of asthma occur in a population over a period of time) of asthma. That leaves us with data that report the prevalence (percentage of current population) of asthma and those potentially at risk of suffering symptoms and morbidity. The prevalence of asthma among children changes with increasing age. As an example, boys have higher current asthma prevalence, compared with girls throughout most of childhood. Table 1 provides generalized details of asthma prevalence rates and relevant data. ${ }^{4-6}$

In addition to an increasing prevalence of pediatric asthma, the number of children seeking medical assistance or treatment for asthma has also increased, as measured by ambulatory visits, emergency department (ED) use, and hospitalizations for asthma. Ambulatory care visits have continued to increase since 2000 . This rising trend poten- 
Table 1. Pertinent Asthma Statistics

\begin{tabular}{lc}
\hline \hline Americans diagnosed with asthma & 34 million \\
Patients $<18$ years old with asthma & 9.6 million $(13.1 \%)$ \\
$\quad$ Males & $17 \%$ \\
Females & $13 \%$ \\
Had an asthma exacerbation in the past year & 12.3 million $(36.1 \%)$ \\
Asthma prevalence in adults & $7.3 \%$ \\
Asthma prevalence in children $<17$ y old & $9.1 \%$ \\
Non-Hispanic black & $17 \%$ \\
Hispanic & $8 \%$ \\
White & $8 \%$ \\
Socioeconomic Status & \\
Poor & $14 \%$ \\
Non-poor & $8 \%$ \\
& \\
(Adapted from References 4-7.) & \\
\hline
\end{tabular}

tially involves increasing disease severity and increased healthcare utilization to maintain asthma control due to enhanced patient and/or provider knowledge. Although asthma prevalence was higher for older children (1117 years of age), healthcare utilization is lower for this age group. The youngest boys ( $0-4$ years of age) used ambulatory care and hospital services more frequently than did girls of the same age, but differences according to sex decreased to insignificant levels in the 11-17-year-old age group. ${ }^{7}$

Increased ambulatory care use for asthma has continued during an era when overall rate of ambulatory care use for children did not increase. ${ }^{7}$ The message of long-term asthma management through regular scheduled physician visits appears to have been successfully understood, as the majority of non-urgent visits occur in physician offices. In 2006 , there were 47 visits to physicians' offices per 1,000 children (3.4 million visits) and 6 visits to hospital outpatient departments per 1,000 children (0.5 million visits). Almost $2 \%$ of all ambulatory care visits among children 0-17 years of age were attributable to asthma. ${ }^{8}$

While the prevalence and use of ambulatory care for pediatric asthma has continued to inch upward over the past several decades, the rates of ED visits, hospitalizations, and mortality for asthma have either held steady or, more importantly, declined. However, asthma remains a major illness in terms of functional morbidity and suffering, and is leading cause of hospitalizations in children $<15$ years of age. Since 1992, when data first became available from the National Hospital Ambulatory Medical Care Survey, the rate of ED visits attributable to asthma among children decreased slightly, by $0.8 \%$ per year, and in 2006 there were 593,000 ED visits attributable to asthma, which represented $2.3 \%$ of all ED visits among children $0-17$ years of age. ${ }^{8}$
While many factors contribute to admission rates among children with asthma, hospitalization symbolizes a severe exacerbation requiring a high level of monitoring and care, at substantial cost. From 1980 through the mid-1990s, the asthma hospitalization rate steadily increased in children under 17 years of age. Trend analysis identified an annual $2.9 \%$ increase from 1980 through 1991, but there has been no statistically significant trend after 1991. Overall nonasthma hospitalizations for children has decreased over that period, whereas the asthma hospitalization rate remained level. ${ }^{9}$ In 2006 there were 21 asthma-related hospitalizations per 10,000 children, for a total of 155,000 hospitalizations; this represented approximately $5.6 \%$ of all hospitalizations among children in $2006 .{ }^{8}$ There has been speculation that this decrease is related to better overall asthma management in the ambulatory environment, but it may be related to a multitude of other reasons, one of which is a higher tolerance of asthma exacerbation severity that requires admission and treatment in an acutecare setting. A recent study by Hartman et al may lend credibility to this theory. ${ }^{10}$ They examined administrative data from New Jersey and concluded that, while fewer children were admitted with status asthmaticus, the proportion of patients managed in pediatric intensive care units (ICUs) was climbing, despite no substantial rate increases in mechanical ventilation or death.

Some believe that disease-related mortality trends are a true reflection of how well a disease is diagnosed, treated, and managed. While trends in ambulatory visits, ED visits, and hospital admissions have multifactorial causes, there is very conclusive evidence that headway has been made in decreasing the frequency of pediatric asthma exacerbation visits and admissions. The children most at risk of dying from asthma are those with severe, uncontrolled asthma, a history of near-fatal attacks, a history of recurrent hospitalization, and exacerbations requiring intubation for asthma. ${ }^{11}$ Trend analysis found that, while asthmarelated mortality increased $3.2 \%$ per year from 1980 through 1996, a reversal thereafter led to an average decrease of $3.9 \%$ per year from 1996 through 2005. In 2005 there were 2.3 asthma-related deaths per million children, for a total of 167 deaths. $^{8}$

\section{Pathophysiology of Asthma}

Airway inflammation is a major factor in the pathogenesis and pathophysiology of asthma. The importance of inflammation to central features of asthma continues to expand and underscore this characteristic as a primary target of treatment. As previously stated, airway inflammation encompasses an alliance of many cell types and dozens of mediators with the airways that ultimately produces characteristic pathophysiological features of asthma: airway inflammation and air-flow limitation that re- 
sult in repeated occurrences of cough, wheeze, and shortness of breath. The means by which these cooperative actions occur and develop into clinical asthma are still under investigation.

Efforts to increase understanding of the pathogenesis of asthma are a key factor leading to its control and cure. Definitively diagnosing asthma in infants and toddlers can be difficult, given the many different etiologies that cause wheezing in very young children. Asthma creates a substantial burden for the estimated 9.6 million children, their families, caretakers, schools, families' employers, and the healthcare system. The epidemiology of the increasing prevalence of asthma is still poorly understood.

Clinicians and researchers have long acknowledged that asthma is not a self-contained disease, but occurs and presents in many different forms. Many clinical reviews have emphasized asthma's multifactorial nature, with relationships between inflammatory cells (mast cells, eosinophils, neutrophils, lymphocytes, and macrophages), their mediators (leukotrienes, prostaglandins, interleukins, and platelet-activating factor), neural mechanisms, and basic malformations of the arachidonic acid pathway and smoothmuscle cells.

Because of the variety of etiologies, asthma is frequently characterized by its heterogeneity, which presents as a vast array of wheezing phenotypes in childhood. Wheezing has been suggested as the most important symptom in identifying asthma in disease population studies. ${ }^{12}$ Asthma can be characterized as a multifaceted disease in which multiple genetic and environmental factors combine to produce a range of pathogenesis and severity. Causative genes discovered to date explain only a small fraction of heritable asthma. Because of this heterogeneity and a lack of definitive biological foundation for asthma from genetics or other causes, classification recently has migrated toward that of asthma phenotypes.

Improved phenotype definition may help in identifying the missing components of heritability. The term phenotype, as introduced by Johannsen and Shull, was intended to characterize different "types" of organisms distinguishable by their observable characteristics (eg, shape, structure, size, and color). ${ }^{13}$ Today, substantial efforts are underway in the search for the variants underlying predisposition to asthma and associated phenotypes: preasthma wheezing, inflammatory markers, infections, atopy, aspirin sensitivity, exercise, severe asthma, flare-prone, lung function, elevated immunoglobulin E (IgE), highly variable time course (prognosis), and bronchial hyper-responsiveness.

Because of this increased focus on asthma phenotypes, asthma guidelines now recommend phenotype-specific treatment. Numerous recent studies have shown that phenotypes can differ in their association with asthma risk factors, ${ }^{13}$ and, more importantly for clinical practice, phe- notypes can differ in their response to long-term treatment modalities. The pressing necessity for developing a consistent and reproducible classification system would facilitate research into etiology and pathophysiology, allow targeted treatment and preventive measures, and improve the prediction of long-term outcomes.

\section{Hereditary Versus Hygiene}

Asthma has historically been recognized as a hereditary disorder. An area of asthma research that continues to be investigated is the association between family history and childhood asthma. Valerio et al recently found that children with asthmatic parents were twice as likely to have asthma, and that the influence of the both parental and grandparental relationship was 4 times more likely to manifest as asthma, regardless of sex, ethnicity, or birth order. ${ }^{14}$ Given the higher than normal prevalence of asthma in certain populations, it appears that asthma family history in first-degree relatives may have a positive predictive value for capturing the probability of childhood asthma. ${ }^{15}$

To highlight this hereditary importance of asthma, the asthma prevalence in different countries ranges from $<1 \%$ in Tibet to $>30 \%$ in New Zealand. ${ }^{16}$ Recent investigation of asthma genomes discovered numerous genes that either are intricately involved with or linked to the presence of asthma or mechanisms of its characteristics. Various genome-wide studies have identified more than 100 genes on 22 different chromosomes associated with asthma. The complexity of genetic association in clinical asthma is demonstrated through relationships to specific phenotypic characteristics, but not automatically to the disease process or clinical symptoms. Atopic diseases, while heritable, are drastically increased by repeated exposure to various environmental factors that can regulate asthma development or diminution through epigenetic encoding. This is exemplified in numerous studies that evidence that genetic backgrounds in different environments produce susceptibility to different allergic disorders. The initial candidate gene approach was largely disappointing, with marginal effects and poor replication between studies. ${ }^{17}$ The genetic effects uncovered are generally small (odds ratio $<1.5$ ), and since the completion of the first genome-wide analyses, it is unlikely that variants with larger effects will be found with this one-dimensional approach. ${ }^{18}$

Increasing evidence continues to underscore the importance of immune factors in the development of asthma and its resulting inflammation processes. The hygiene hypothesis is an evolving theory devised to explain the increasing prevalence of allergies and asthma in many technologically developed countries, compared to less technologically developed countries. The hygiene hypothesis is that an abnormally clean environment, which lacks early-childhood exposure to asthma triggers and sensitization and 
infection, causes a "naïve" immune system and thereby dramatically increases the incidence of allergy and asthma.

Increasing scientific evidence has supported the theory that an imbalance between T-helper-1 (Th1) and Th2 cytokines explains and predicts the development of asthma. The foundation of this hypothesis is that the newborn's immune system is skewed toward Th2 cytokine production. Following birth, various environmental stimuli, such as microbial exposure and infections, activate Th1 reactions and cause the Th1/Th2 relationship to become imbalanced. However, research efforts to demonstrate an infection/asthma relationship have not been successful, and have led to disappointment for those promoting the hypothesis. In fact, David Strachan (the father of the hygiene hypothesis) stated that, "the totality of current evidence from the cross-sectional and longitudinal studies of common specific and non-specific infectious illness in infancy and childhood offers no support for the hygiene hypothesis." ${ }^{19}$ However, though science has not found strong support for either hereditary or hygiene factors, these theories have not been invalidated either. The pathogenesis of asthma is probably related both to genetic predisposition and to over-exposure or under-exposure to viruses or other environmental factors.

\section{Environmental Conditions}

While the hygiene hypothesis has not produced direct correlation to asthma, living in certain environments or neighborhoods is definitely associated with higher risk of developing asthma and with worse outcomes. Tobacco smoke, air pollution, and other environmental variables, and respiratory infections and diet are associated with higher asthma risk, although the association has not been as clearly established for allergens and respiratory infections..$^{20,21}$

Tobacco smoke contains many known toxic chemicals and irritants. Tobacco exposure is probably the strongest known environmental modifier of the natural history of asthma. Children exposed to tobacco smoke have more asthma exacerbations and other problems, including lower-respiratory infections and middle-ear infections. A mother's smoking status was associated with a $7 \%$ deficit in lung function among newborns in a comprehensive risk analysis in the Copenhagen Studies on Asthma in Childhood (COPSAC) cohort. ${ }^{22}$ In utero exposure to environmental tobacco smoke increases the likelihood of wheezing in the infant, and particularly the likelihood of disease in the first years of life, although the subsequent development of asthma has not been well defined. ${ }^{23,24}$

Preschool children are more likely to be exposed to environmental tobacco smoke in their homes than in public places. ${ }^{25,26}$ However, simply "smoking outside" or "not in the presence of the child" is not enough to limit harm to children from tobacco smoke. Smoke settles on clothes,
Table 2. Findings From a Study of Asthma Outcomes Relative to Outdoor Air Pollution Exposure

High levels of local traffic emissions is associated with new onset of asthma in children

Residences within 75 meters of major roadways have:

1.5 times higher risk of lifetime asthma and wheeze

3 times higher respiratory-related school absences

Reducing the patient's exposure to polluted air improves lung function and reduces asthma symptoms

(Adapted from Reference 29.)

hair, car upholstery, and furniture. A recent clinical trial on limiting children's exposure to secondhand smoke found no statistically or clinically important effect in decreasing secondhand exposure, as measured via cotinine-to-creatinine ratio or asthma-related healthcare utilization, which is not so unusual in the history of effective tobacco-control interventions. ${ }^{25}$

A recent retrospective study by Mackay et al suggests that interventions to reduce secondhand smoke exposure improve outcomes in patients with asthma. ${ }^{27}$ They analyzed pediatric asthma hospital admissions data in Scotland from 2002 to 2009 and found that after implementation of smoke-free legislation the asthma admissions rate decreased $18.2 \%$ per year $(95 \%$ CI $14.7-21.8 \%, P<.001)$, relative to the March 2006 rate. The reduction was apparent in both preschool and school children.

The role of air pollution in the development of asthma remains controversial, and may be related to allergic sensitization. ${ }^{28}$ Air pollution includes a wide range of toxic substances, including industrial and vehicle emissions, particulates from wood and gas stoves, volatile organic compounds, and other indoor and outdoor airborne substances. The relationship between air pollution levels, asthma exacerbations, and ED visits is well documented. One epidemiologic study found that frequent and substantial exercise ( $\geq 3$ team sports) outdoors in communities with high ozone concentrations was associated with a higher risk of asthma among school-age children (Table 2). ${ }^{29}$

The role of environmental asthma triggers is well recognized and is included in the National Asthma Education and Prevention Program guidelines. ${ }^{30}$ Children spend a substantial percentage of their lives indoors. United States residents as a whole spend up to $60 \%$ of their time inside their homes, and a substantial portion of the remaining time in other indoor environments, such as school or workplace. ${ }^{31}$ Long-term exposure to normal and typical indoor allergens can lead to allergic sensitization and stimulate allergic symptoms in children. A causal relationship between allergen exposure early in life and risk of subsequent sensitization has yet to be well established and remains a matter of debate. ${ }^{32}$ 
After allergen skin testing has been performed, environmental assessment is essential for the identification and quantification of indoor allergens. A study by Sheehan et al showed an increase in the rate of sensitization to indoor and outdoor aeroallergens throughout childhood, and found different aeroallergens to be prominent at different ages. ${ }^{33}$ The study also provided insight into that cohort of children, that $57.2 \%$ who underwent skin-prick testing were sensitized to at least one of the studied aeroallergens. In addition, $51.3 \%$ of patients were sensitized to at least one indoor aeroallergen, and 38.8\% were sensitized to at least one outdoor aeroallergen.

Studies, such as the inner-city asthma study of individualized, home-based environmental interventions for hundreds of children in major United States cities, have demonstrated that environmental interventions decrease exposure to allergens and reduce asthma-associated morbidity. ${ }^{34}$ Interventions to decrease allergen exposure below sensitization and symptom thresholds are possible with various remediation techniques. While home-based interventions or educational endeavors have proven successful, healthcare education programs and pediatric practices do not typically include environmental aspects of pediatric asthma management. A study by Kilpatrick et al reported that over half of practicing pediatricians surveyed had seen a patient with health issues related to environmental exposures, but $<25 \%$ were trained in taking an environmental history. ${ }^{35}$

Throughout infancy, a variety of respiratory-related viruses have been linked with the establishment or development of asthma. In early life, the 2 main viral etiologies associated with asthma development are respiratory syncytial virus and parainfluenza virus. Long-term prospective studies of children admitted to hospital with documented respiratory syncytial virus show that approximately $40 \%$ of these infants will continue to wheeze or have asthma in later childhood. ${ }^{36} \mathrm{~A}$ more recent virus of interest in wheezing and asthma development is symptomatic rhinovirus in early life. The influence of viral respiratory infections on the development of asthma may depend on an interaction with atopy. The atopic state can influence the lower-airway response to viral infections, and viral infections may then influence the development of allergic sensitization.

The prevalence of childhood obesity, defined as body mass index $>95$ th percentile, based on historical reference populations, is approximately $17 \%$ in the United States. ${ }^{37}$ The increasing rate of obesity has paralleled the increasing asthma prevalence, but the relationship with asthma is uncertain. ${ }^{38}$ Obesity and asthma are now among the most common chronic diseases of childhood. ${ }^{38,39}$ Obesity's propensity to develop certain inflammatory mediators may be a risk factor for asthma that leads to an enhanced or increased airway dysfunction.
A recent prospective trial by Ginde et $\mathrm{al}^{40}$ assessed the prevalence of obesity among children presenting to the ED with acute asthma, and examined the relationship between body mass index and acute and chronic asthma severity in the ED setting. The prevalence of obesity in the study group was $23 \%$ (95\% CI 20-26\%), which was significantly greater $(P<.001)$ than the reported rate $(9-15 \%)$ in children in the general population around the time of data collection. The prevalence of overweight (body mass index $>85$ th percentile) in the study group was 39\%, which was significantly greater $(P<.001)$ for patients with asthma than in the general population, where the prevalence was approximately $25 \%$. The prevalence of obesity in the study group was similar to that among children with physician-diagnosed asthma in the general population (23\% vs $21-30 \%$ ), but significantly higher than that among all children in the general population (23\% vs 9-15\%). Ginde et al concluded that asthma exacerbations among obese children are very similar to those among other children.

\section{Sociocultural Factors}

Children with asthma who live in high-poverty and lowopportunity communities have disproportionately high adverse asthma outcomes. There are racial disparities in asthma in ED visits, hospitalizations, and death, which are substantially higher than prevalence disparities alone. The disparity in asthma mortality between black and white children recently increased. Black children in families with incomes $<50 \%$ of the poverty level (approximately $\$ 10,000$ for a family of 4) have twice the risk of asthma as white children in the same financial situation.

A retrospective study by Piper et al examined the correlates of access to care among children $(<17$ years old $)$ with asthma, ${ }^{41}$ and the relationship of childhood asthma healthcare utilization and racial and income differences in the United States. The findings indicated disparities among black children with asthma and their ability to access appropriate healthcare services. Piper et al believed the study's results are nationally representative and consistent with previous studies that suggested that being uninsured impacts an individual's ability to access the healthcare system. They concluded that in the United States uninsured children with asthma, especially black children, have marked disparities in their ability to access appropriate healthcare services.

But we should not hastily conclude that it is only the uninsured, socioeconomically disadvantaged who suffer disparities in childhood asthma. In a study funded by the Health Resources and Services Administration, Kogan et al determined that, in 2007, 11 million children were without health insurance for all or part of the year, and $22.7 \%$ of children with continuous insurance coverage (14.1 million 
children) were underinsured. ${ }^{42}$ Those most likely to be underinsured were older children, Hispanic children, children in fair or poor health, and children with special healthcare needs. In fact, compared to children who were continuously and adequately insured, uninsured and underinsured children were more likely to have problems with healthcare access and quality.

But neither should we conclude that childhood asthma disparities are prevalent only in children with no or insufficient insurance. A retrospective cohort analysis by Stewart et al, ${ }^{43}$ in the military health system, assessed racial and ethnic differences in asthma prevalence, treatment patterns, and outcomes among a diverse population of children with equal access to healthcare. The theory behind the study was that the military health system provides comprehensive health insurance to a racially and ethnically diverse population, so studying disparities in healthcare treatment and outcomes in that population could substantially improve our understanding of possible effects of universal coverage on reducing disparities in healthcare. Black and Hispanic children in all age groups were significantly more likely to have an asthma diagnosis than white children. Black children in all age groups and Hispanic children ages 5-10 years were significantly more likely to have potentially avoidable asthma hospitalizations and asthma-related ED visits, and were significantly less likely to visit a specialist than were white children. Black children in all age categories were significantly more likely to have filled prescriptions for inhaled corticosteroids (ICS) than were white children. Stewart and colleagues concluded that, despite the entire study cohort having the same health insurance coverage, there were racial and ethnic differences in asthma prevalence, treatment, and outcomes.

In summary, there are disparities in access to care, prevalence, treatment, and outcomes among children with asthma. Racial inequalities, inadequate insurance, and an impoverished economic standing all negatively impact morbidity and mortality in children with asthma. More scientific investigation and targeted interventions must assess our ability to equilibrate these factors and produce appropriate and acceptable outcomes for children with asthma in the United States.

\section{Diagnosis, Assessment, and Monitoring}

The majority of children with asthma experience their first asthma symptoms before 6 years of age. Furthermore, data also suggest that events occurring during fetal or early life, such as the development of immune responses, cytokine dysregulation, and responses to microbes, are important risk factors for asthma. Changes in airway function also appear to develop early in life and early in the course of asthma. These facts make early and accurate diagnosis a key component of effective asthma treatment and management.

Approximately three fourths of patients diagnosed with asthma are diagnosed prior to starting elementary school. Spirometry is the accepted standard for asthma diagnosis and monitoring. Spirometry is the most widely performed pulmonary diagnostic test in school children, adolescents, and adults for respiratory disorders. However, a recent study by Dombkowski et $\mathrm{al}^{44}$ found that the use of spirometry in primary-care settings in children with asthma does not conform to the national guidelines. And implementing those guidelines will probably require a major educational initiative to address deficiencies in spirometry interpretation and other barriers, which may drive diagnostic testing to tertiary-care facilities with the appropriate equipment and staff to diagnose asthma in pediatric patients.

The possibility of obtaining reproducible flow/volume curves in young children was recently reported, and, despite relatively few data in this age group, our knowledge is sufficient to give advice on how to perform spirometry in young children. ${ }^{45}$ Despite recent successes in the research environment, spirometry's practicability outside the research arena and highly trained specialized laboratories makes its value uncertain in the real world of daily asthma management. While pre-school PFTs are undoubtedly excellent research tools, more research is needed to monitor progress and measure the effect of interventions in the individual patient. ${ }^{46}$ This has led clinicians to look for more user-friendly means of diagnosing and monitoring asthma in children $<7$ years of age.

\section{Exhaled Nitric Oxide}

In recent years, the exhaled nitric oxide (NO) concentration has raised the expectations of clinicians as a useful monitoring tool in asthma management. The exhaled NO concentration is elevated in asthma, especially when eosinophilic inflammation is present, and elevated exhaled NO predicts response to steroid treatment. ${ }^{47}$ Currently asthma guidelines do not recommend monitoring inflammation directly: only monitoring indirect indicators of inflammation such as symptoms and lung function. Measurement of exhaled NO is a patient-friendly and noninvasive way of assessing airway inflammation. Adding exhaled NO measurement to asthma diagnosis would provide clinicians with diagnostic tools to assess all 3 main asthma characteristics: symptoms, air-flow obstruction, and inflammation. Exhaled NO can be easily, quickly, and repeatedly measured in children.

In a large European cohort study conducted to see if objective measures could be utilized to predict whether preschool children with symptoms suggestive of asthma would develop asthma in later childhood, Caudri et al 
concluded that both exhaled NO and specific IgE measured at age 4 (but not interrupter resistance), improved the prediction of asthma symptoms until the age of 8 years, independent of clinical history. ${ }^{48}$

Elevated exhaled NO indicates uncontrolled airway inflammation and calls for the initiation or increase of steroid treatment. The finding that exhaled NO decreased with the implementation of corticosteroids led to further investigations into exhaled NO's clinical utility. Proof-ofconcept studies on exhaled NO measurement showed positive and neutral impact for routine monitoring of asthma treatment in children. However, before recommending widespread use of exhaled NO outside the practice of asthma specialists, studies are needed to determine the inflammation cut-off level and assess to what extent individual monitoring rather than generic cut-off level improves asthma outcomes. ${ }^{49}$

A Cochrane analysis ${ }^{50}$ concluded that tailoring the ICS dose based on exhaled NO (versus based on clinical symptoms) was carried out in different ways in the 6 studies, that there was only modest benefit at best, and that children monitored with exhaled NO measurements received higher doses of ICS. Tailoring the ICS dose based on exhaled NO monitoring cannot be recommended for routing clinical practice at this stage, and remains uncertain. The current approach is that a decrease in exhaled NO to a desired range may not be the correct clinical strategy; perhaps it would prove more useful to compare the results to the patient's previous values, as with pulmonary function tests.

\section{New Innovations}

Recent research and development has led to an innovative diagnostic approach to assist with wheeze identification, characterization, and quantification. Lung-sound analysis is objective, noninvasive, and correlates with clinical status in asthma and bronchiolitis. ${ }^{51}$ The Pulmotrack and Wheezeometer (both by KarmelSonix, Rancho $\mathrm{Cu}$ camonga, California) enable continuous monitoring of wheezes, without patient cooperation, which makes them potentially ideal tools for young children with asthma. In addition to quantifying and recording, these devices provide: wheeze by wheeze identification, accurate measurement of wheeze rate (the proportion of wheezing within the respiratory cycle), respiratory rate, inspiratory-to-expiratory ratio, and classification of wheezes as inspiratory or expiratory. The Pulmotrack device has been successfully used in bronchoprovocation testing in infants and other non-cooperative subjects, ${ }^{52}$ and in bronchodilator response-to-treatment testing. ${ }^{53}$

In the past few years there has been growing interest in the lung-clearance index, which measures lung physiology based on multiple breath-washout tests. ${ }^{54}$ The lung-clear-
Table 3. Definitions Recommended by a Joint Task Force of the American Thoracic Society and European Respiratory Society on Asthma Control and Severity

Asthma severity is defined as the difficulty in controlling asthma with treatment, after exclusion of modifiable factors such as poor adherence, smoking, and comorbidities. Severity largely reflects the required level of treatment and the activity of the underlying disease state during treatment.

Asthma control encompasses not only the patient's recent clinical state (symptoms, night waking, reliever use, and lung function), but also considers their future risk, which is their potential for experiencing adverse outcomes such as loss of control in the near or distant future, exacerbations, accelerated decline in lung function, or treatment-related adverse effects. It is emphasized that even if current poor control predicts future poor control and health care utilization, other pathologic and physiologic variables also influence future risk, independent of the level of current clinical control.

ance index is expressed as the number of lung volume turnovers required in normal breathing to clear the lungs of a blood-insoluble tracer gas down to one 40th of its starting concentration. The lung-clearance index is ideal for use in children, because it requires only tidal breathing and has good repeatability. The rationale for the lungclearance index is the importance of early identification of airways dysfunction, prevention of irreversible structural airway changes, and the need for a method of monitoring airway disease in these "silent years." In pediatric patients the lung-clearance index can detect early airways disease with better sensitivity and ease of use than can conventional lung-function tests. ${ }^{55}$

As these devices and measurements are relatively new and have not been validated in large clinical trials, their overall impact on asthma diagnosis, monitoring, treatment, and management remains to be seen.

\section{Asthma Severity}

The mechanisms that underlie asthma severity are poorly defined. Many factors probably play a role in determining severity, but the primary 2 are probably immune (innate, adaptive, or immune tolerance) and inflammatory responses. The differences are in their remodeling responses or in ways that alter sensitivity of their airway target tissues. The translation of these immunopathology responses to asthma persistence and severity, and, most importantly, structural and functional changes has not been clearly established.

The initial treatment guidelines published in the 1990s were centered on disease severity grading: intermittent and mild, moderate, and severe persistent asthma. Early in the 21 st century, the focus shifted toward guideline-defined asthma control and the fact that achievement of good control is associated with improved health status. ${ }^{56,57}$ Peder- 


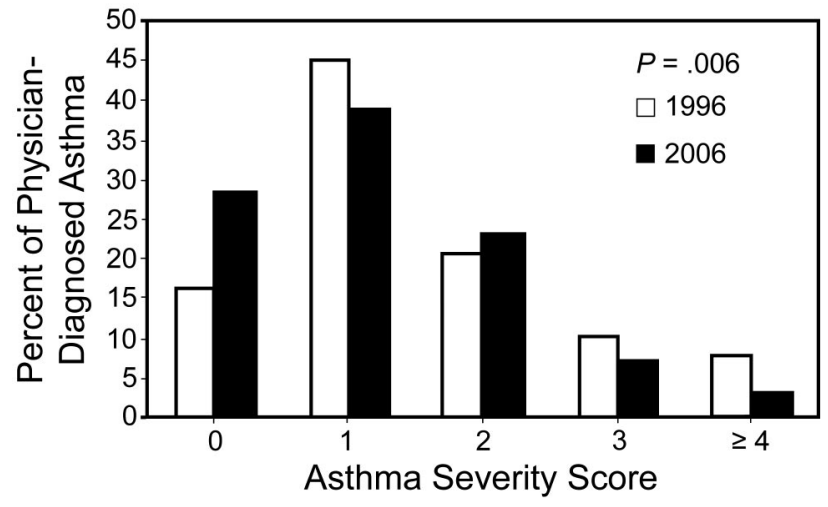

Fig. 1. Asthma-severity score among children with physician-diagnosed asthma in 1996 and 2006. The $P$ value was calculated using one-way analysis of variance. (Adapted from Reference 58.).

sen clearly delineated asthma severity versus asthma control (Table 3). ${ }^{58}$

Asthma severity scoring and asthma management based on disease-control concepts are covered in great detail elsewhere. ${ }^{59}$ I hypothesize that, after several decades of focus on guideline-based asthma diagnosis, assessment, and treatment, the message may be finally producing the desired outcomes. A recent Swedish study by Andersson et al provided the first evidence of a possible decline in asthma severity. ${ }^{60}$ The proportion of children with physician-diagnosed asthma using ICS increased from $54.8 \%$ in 1996 to $67.0 \%$ in $2006(P=.01)$, while the corresponding proportion of users of short-acting $\beta$ agonists (SABAs) decreased from $85.3 \%$ to $77.0 \%$ ( $P=.036$ ). The asthmaseverity score indicated a decrease in the proportion of children with more severe symptoms $(P=.006)$ (Fig. 1). The increase in the proportion of children with asthma using ICS and the introduction of long-acting $\beta_{2}$ agonists (LABAs) parallels a major decrease of severe symptoms and probably explains this decrease.

\section{Pharmacology}

When it comes to asthma pharmacology, one might quickly conclude that "the more things change, the more they stay the same." In 2006, Peter Barnes wrote about asthma pharmacology that:

It is of interest that many of our effective therapies for asthma were originally derived from natural substances. Many were isolated from plants through the discovery of herbal remedies, including atropine, dietary xanthines such as theophylline and chromones from a Mediterranean medicinal herb. The most effective treatments for asthma are derived from hormones, b-adrenoceptor agonists from adrenaline and corticosteroids from cortisone, both secreted by the adrenal gland. Indeed, the most effective therapies available for asthma so far are combination inhalers containing a LABA and a corticosteroid. ${ }^{61}$

In 2010, anti-histamines, cromones, and xanthines have virtually disappeared from the routine asthma armamentarium and utilization recommendations in evidenced-based guidelines. In fact, one might conclude that we are left with chemically refined derivatives of adrenaline and cortisone for acute symptomatic and asthma exacerbation management. While these 2 classes of medications have been the mainstays for almost 40 years, they certainly are improved in terms of safety and therapeutic index; however, they are still associated with well recognized adverse effects, and far from being the magic bullet cure we have been waiting for with each exciting discovery in asthma pathogenesis, diagnosis, or pharmacology.

\section{Quick-Relief Medications}

Short-Acting $\boldsymbol{\beta}_{\mathbf{2}}$ Agonists. SABAs are the most effective asthma therapy for rapid relief of symptoms and quick reversal of air-flow obstruction. The clinical utility of SABAs is due to their fast onset ( $\leq 5 \mathrm{~min}$ ), peak action within $30-60 \mathrm{~min}$, and duration of $4-6$ hours. Frequent ( $\geq 4$ times daily) and long-term use of SABAs does not affect potency but is associated with reduced duration of action. ${ }^{62,63}$ Based on these characteristics, the National Asthma Education and Prevention Program Expert Panel Report 3 recommends using SABAs only when necessary for symptom relief or before anticipated exposure to known asthma triggers (eg, animals, exercise). ${ }^{64}$ Puffs can be taken in 10 15 -second intervals; longer intervals offer no additional benefits. ${ }^{65}$

Anticholinergics. Anticholinergic bronchodilators such as ipratropium are not recommended as monotherapy for quick relief of asthma symptoms. ${ }^{64}$ They have a longer onset of action (20-30 min) and cause less bronchodilation than inhaled $\beta_{2}$ agonists. ${ }^{66}$

Steroids. ICS, because of their delayed onset of action, are insufficient in the treatment of moderate to severe exacerbation. ${ }^{64}$ Instead, oral systemic steroid treatment is the global recommendation: $1-2 \mathrm{mg} / \mathrm{kg} / \mathrm{d}$ for 3-10 days in children. Tapering of short-term oral steroid dosing is not necessary in asthma. ${ }^{67}$

\section{Controller Medications}

Controller medications are the basis of care for children with persistent asthma and must be taken daily to maintain 
symptom control. The major classes of controller medications are ICS, LABAs, leukotriene-receptor antagonists, and humanized monoclonal antibodies.

Inhaled Corticosteroids. ICS remain the cornerstone of asthma management once a child is determined to have any level of persistent asthma. The ideal ICS for pediatric asthma should have high pulmonary deposition, low systemic bioavailability, and rapid systemic clearance, to maximize effectiveness while minimizing adverse effects. There are minimal clinically meaningful differences among the various types of ICS. ${ }^{68}$ The bronchoprotective effects of ICS delivered via dry-powder inhaler or hydrofluoroalkane-propelled metered-dose inhaler (MDI) are equivalent. ${ }^{69,70}$

In the United States, beclomethasone, fluticasone, and budesonide have been used for many years as the predominant ICS in long-term management of pediatric asthma. With the recent introduction of mometasone and ciclesonide, additional options for dosing and delivery have become available. Mometasone (for patients $\geq 12$ years old) and ciclesonide (for patients $\geq 4$ years old) are both FDA approved for once-daily use - a potential benefit toward better adherence.

The most arbitrary component of step-wise management of chronic asthma is increase and decrease of ICS being based on symptoms and age of the child. A recent Cochrane review concluded that commencing with a moderate ICS dose is as effective as commencing with a high ICS dose and then reducing the dose while monitoring symptoms. There was no benefit in doubling or quadrupling the starting ICS dose. Therefore, patients should start treatment with a low to moderate ICS dose. ${ }^{71}$

A recent meta-analysis by Zhang et al assessed the doseresponse relationship (benefits and harms) of ICS in children with persistent asthma ${ }^{72}$ and found that, compared to a low ICS dose, a moderate ICS dose does not provide clinically relevant therapeutic advantage in children with mild to moderate persistent asthma. Additional randomized controlled trials are needed to clarify the dose-response relationship of ICS in persistent childhood asthma.

Long-Acting $\boldsymbol{\beta}_{\mathbf{2}}$ Agonists. LABAs are a unique class of bronchodilators with duration of action of $>12$ hours. Since these drugs are $\beta_{2}$-adrenergic-receptor-specific, the occurrence of tremor, palpitations, and tachycardia are typically low, compared to the SABAs. While regular use has not been found to cause substantial tachyphylaxis in duration of action, it does somewhat diminish the bronchoprotective effect. ${ }^{73,74}$

Concerns about the safety of LABAs arose after reports of more severe exacerbations and deaths, in both adults and pediatrics, when LABA was added to usual asthma therapy ${ }^{75}$ This prompted the FDA to review these medi- cations and add a new warning label that strongly suggests that LABAs should never be used as monotherapy for long-term control of persistent asthma. ${ }^{64}$

Combination formulas of ICS plus LABA have been extensively studied in patients $\geq 12$ years old, but not in children $<4$ years old. Numerous studies have found excellent control of moderate persistent asthma with combination therapy in patients $\geq 12$ years. ${ }^{64}$ These clinical data indicate that the combination of ICS plus LABA leads to clinically meaningful improvements in lung function and symptoms, and reduces the need for quick-relief SABAs.

Step-down strategies in combination therapy (LABA plus ICS) may mean changing to a new device for a lower dose of inhaled steroid, which can require 2 separate devices and 2 co-pays. ${ }^{68}$ However, a recent study by Eid et al found that once-daily budesonide/formoterol had significantly better efficacy than once-daily budesonide alone for most pulmonary function variables. Also, twice-daily LABA plus ICS maintenance therapy was generally more effective than stepping down to once-daily dosing. ${ }^{76}$

Leukotriene Receptor Antagonists. Leukotriene receptor antagonists are a substitute, less preferred, treatment for children with mild persistent asthma. Leukotriene-receptor antagonists can also be used as adjunct with ICS, but are not preferred for patients $\geq 12$ years old, in lieu of ICS being combined with LABAs. Leukotriene receptor antagonists have the advantages of ease of use and high patient adherence to therapy, ${ }^{77}$ and they can provide good control of asthma symptoms in many patients.

As an add-on therapy to ICS in children, montelukast provides asthma control equal to that of doubling the baseline dose of ICS; however, there is a higher exacerbation risk with montelukast. ${ }^{78}$ A systematic review determined that the addition of montelukast as an add-on to ICS (versus ICS alone) increased asthma-free days and decreased nocturnal awakenings and exacerbation events. ${ }^{79}$ Therefore, montelukast remains a reasonable add-on to ICS or ICS/LABA combination therapy in patients who are not well controlled on ICS alone. In a recent study, Virchow et al found that in patients insufficiently controlled with either ICS or combination therapy, the daily add-on of leukotriene-receptor antagonist improved both asthma control and asthma-related quality of life. ${ }^{80}$

\section{Adjunctive Therapies}

Methylxanthines: Methylxanthines have been long associated with the management and treatment of asthma, and, in this class of drugs, theophylline is the main medication in the United States today. Theophylline is a mild to moderate bronchodilator and may have mild anti-inflammatory effects. Theophylline is likewise cited in the 
guidelines as adjunct to ICS. However, the availability of alternative drugs and the dose-related acute toxicity that mandates monitoring serum concentration has limited theophylline's use in pediatric practice.

Humanized Monoclonal Antibodies. Immunomodulators are the newest class of asthma medications to be approved and used in patients. Omalizumab is a humanized monoclonal antibody that binds with free $\operatorname{IgE}$ and is indicated for atopic patients with asthma not controlled despite adherence to controller therapy. Its unique advantages and potential steroid-sparing effect have been invoked, but there are concerns regarding its cost and insufficient pediatric experience. Omalizumab is used as additive therapy for patients $\geq 12$ years old with severe persistent asthma and a hypersensitivity to inhaled allergens. The potential for anaphylaxis with this medication led to an FDA warning label and further clinical investigations. Because of the additional monitoring required for its use, omalizumab should be reserved to asthma subspecialists.

\section{Asthma Pharmacology Future}

A major problem facing new drug development is that existing asthma therapies, particularly combination inhalers, are highly effective, relatively inexpensive, and safe, and there is a strong scientific rationale for this approach to asthma therapy. ${ }^{81}$ Over the past 2 decades new therapies that made it from bench to bedside have been limited to leukotriene modifiers and anti-IgE humanized antibodies, whose use is limited to second-line or third-line therapy by all guidelines. They are clearly less effective, and their safety records have been questioned recently. This is hardly a revolution, but at least those made it to the market, in contrast to many other shining stars that rapidly turned into meteors, such as the anti-IL5 monoclonal and other biological derivatives that failed to make it to market.

The need for enhanced efficacy and efficiency continues for pediatric asthma. Consistent evidence indicates that ICS improves symptom control and reduces asthmarelated hospital admissions, but recent studies found that ICS does not alter the natural course of asthma or cause long-lasting improvement of lung function in early life. ${ }^{82}$ There is a clinical need for more effective therapies for severe asthma not well controlled by current therapies. Although patients with severe asthma constitute $<5 \%$ of the asthma population, they account for $>50 \%$ of healthcare spending on asthma. New asthma treatments under investigation include inhibitors of the pro-inflammatory enzymes (PDE4), p38 mitogen-activated kinase, and nuclear-factor-kB activating kinase (IKK2). ${ }^{83}$

More specific approaches include inhibiting chemokine receptors on eosinophils and $\mathrm{T}$ lymphocytes, inhibiting adhesion molecules that recruit key inflammatory cells, and inhibiting mast cells with spleen tyrosine kinase inhibitors. Antibodies that block IgE have been introduced and have clinical efficacy in patients with severe allergic asthma. ${ }^{84}$ There is now interest in vaccination approaches that, in patients with asthma, divert the immune system back to normal, but the dangers of that approach have not been determined. Table 4 lists categories of drugs being researched. ${ }^{84}$

\section{Drug Delivery Techniques}

Delivery errors frequently transpire with various aerosol devices, as each device requires precise instructions and specific patient efforts to obtain correct and maximal drug delivery. As management of chronic airway disease is $10 \%$ medication and $90 \%$ education, the proliferation of inhaler types may be disadvantageous for the quality of care. ${ }^{85}$ Appropriate device selection, education, and patient technique are often overlooked when prescribing medications for the management of pediatric asthma.

It is imperative that all clinicians become familiar with the nuances of each and every delivery device so that they can make their patients more knowledgeable. In a systematic review, the mean percentages of patients who used their inhalers without mistakes were $63 \%$ with MDI, $75 \%$ with breath-actuated MDI, and 65\% with dry-powder inhaler. ${ }^{86}$ But this knowledge and education is not just for the patients: it also must be passed along to caregivers in a pediatric setting.

In a recent trial, Welch and colleagues assessed the abilities of caregivers of young children with asthma. Despite standardized initial education on proper use of the prescribed devices, the caregivers made device errors, some of which were of the types that could result in poor lung delivery, thereby giving less-than-optimal clinical results. ${ }^{87}$

Addition of a spacer or valved holding chamber (VHC) can decrease pharyngeal drug deposition and improve lung delivery, but makes the system less portable than MDI alone. While accessory devices have been developed to minimize patient/device interface problems, the accessory devices can produce additional problems. ${ }^{88}$ Many patients mistakenly believe that pausing before inhaling from a spacer or VHC after the MDI is actuated has no effect on the delivered dose. That incorrect technique can significantly reduce drug availability. ${ }^{89}$ Rau also found that dose availability can be significantly reduced with multiple actuations into the spacer or VHC simultaneously.

In a recent trial, Schultz et al studied the number of breaths required to inhale albuterol from several different spacers and VHCs. In young children, the tidal breaths through the spacer or VHC were much larger than expected. Two tidal breaths were adequate with the small-volume VHCs and with a 500-mL modified soft drink-bottle, and 3 tidal breaths were adequate with the larger VHC. ${ }^{90}$ 
Table 4. Categories of Drugs Being Investigated for Future Use in Asthma Management and Treatment

New bronchodilators
Inhaled corticosteroids
Lipid mediators blockers
Cytokine modulators
Cytokine blockade
Cytokines as therapy
Chemokine antagonists

Novel anti-inflammatory treatments

Phosphodiesterase inhibitors

Kinase inhibitors

Adhesion molecule blockade

Peroxisome proliferator-activated receptor $\left(\mathrm{PPAR}_{\mathrm{Y}}\right)$ agonist

Anti-allergy treatments

Anti-IgE therapy

Mast cell inhibitors

Spleen tyrosine kinase (Syk) inhibitors

Improved and specific immunotherapy

Targeting regulatory $\mathrm{T}$ cells

Targeting dendritic cells
Both longer duration of action and once daily muscarinic antagonists

Safer with reduced oral bioavailability, reduced absorption from the lungs or inactivation in the circulation

Drugs that would block the release of over 100 inflammatory mediators

Blockade of cytokine's role in chronic inflammation and in remodeling airway structure

Blocking cytokines that regulate immunoglobulin E ( $\operatorname{IgE}$ ) formation, particularly in severe asthma

Some cytokines are asthma inflammatory process inhibitors and may be therapies

Appropriate targets for therapy, particularly as they signal through G-protein coupled receptors, for which small molecule inhibitors could be developed

Alternative oral anti-inflammatory therapies that might also be effective in treating associated allergic diseases

Wide spectrum of anti-inflammatory effects, inhibiting T cells, eosinophils, mast cells, airway smooth muscle cells, epithelial cells, and nerve cells, and are very effective in animal models of asthma

Regulating the expression of inflammatory genes in asthma, but might have adverse effects as they target mechanisms found in many cell types

Adhesion molecules blockade to inhibit inflammatory cells from the circulation into the airways

Wide spectrum of anti-inflammatory effects, including inhibitory effects on macrophages, $\mathrm{T}$ cells and neutrophilic inflammation, and polymorphisms of the PPAR ${ }_{Y}$ gene

Drugs that target the underlying allergic inflammation

More potent anti-IgE antibodies that might have a broader spectrum of effects

Drugs that target mast cell release of bronchoconstrictor mediators

Block the release of spleen tyrosine kinase involved in activation of mast cells and other immune cells

Target the immune deviation in asthma

Specific immunotherapy targeting regulatory-T-cell expression of interleukin 10, which suppresses Th1 and Th2 responses with marked suppression of $\operatorname{IgE}$ synthesis

Drugs that target dendritic cells' role in chronic asthma inflammation through cytokines and chemokines release
The choice of inhaler devices is determined first by choice of drug, device availability, and reimbursement restrictions. However, proper aerosol delivery technique is crucial to ensure that the patient receives the prescribed dosage and obtains the medication's benefits. An inappropriate choice of delivery system and/or inadequate patient education can thwart an appropriate choice of medication. As an example, the child's age should guide the selection of the ICS delivery device: either a dry-powder inhaler or an MDI without a spacer or VHC. We should bear in mind that children differ in their developmental and cognitive abilities to cooperate and follow instructions, so device selection should be tailored for each patient.

\section{Acute and Ambulatory Care Management}

\section{Emergency Department Treatment}

When a child presents to the ED with an asthma exacerbation, a systematic process that allows patient evalua- tion and triaging with quick assessment of exacerbation severity and the need for urgent intervention is a key mechanism of care. A brief history and limited physical examination should be performed without delaying treatment; frequently the history and physical is performed while the child receives initial treatment.

Asthma management guidelines suggest administration of supplemental oxygen to target an $\mathrm{S}_{\mathrm{pO}_{2}}$ of $92 \%$, inhaled SABAs, and systemic corticosteroids if no response is achieved with $\beta$ agonist. The exact dose and timing of interventions and the use of additional pharmacologic or adjunctive therapies depend on the severity of the exacerbation and the response to initial therapy. The guidelines recommend that inhaled SABAs should be administered immediately on presentation, and repeated up to 3 times within the first hour after presentation. ${ }^{64}$

The preferred dosing and delivery method may differ slightly with each situation, but it is widely accepted that in a severe exacerbation a unit dose $(2.5 \mathrm{mg})$ of albuterol via small-volume nebulizer is preferred. SABA delivery 
has also been demonstrated to be effective when administered as 6-8 MDI puffs every 20 min for up to 4 hours, and then every 1-4 hours as needed, although the results depend greatly on the use of a VHC to ensure maximum deposition in the smaller airways.

The decision of whether to use an MDI or a smallvolume nebulizer depends on the experience of the ED personnel and the patient's asthma severity. In a child who portrays marked distress it is much more effective to use a small-volume nebulizer, because the child may be unable to perform good MDI technique, which is imperative for successful MDI delivery. In a severe exacerbation, albuterol can be delivered via nebulizer, either intermittently or continuously.

A meta-analysis of results from 6 randomized trials indicated that intermittent administration and continuous administration have similar effects on both lung function and the overall rate of hospitalization, whereas a Cochrane review of findings from 8 trials suggested that continuous administration resulted in greater improvement in PEF and $\mathrm{FEV}_{1}$ and a greater reduction in hospital admissions, particularly among patients with severe asthma. ${ }^{91}$

Anticholinergics have a 3-fold slower onset of action than SABAs, and are not recommended as monotherapy in the ED. Ipratropium bromide (dosage $0.5 \mathrm{mg}$ ) may be combined with albuterol and is effective when used in acute air-flow obstruction or severe exacerbation. ${ }^{92}$ Routine use beyond severe air-flow obstruction or during severe exacerbation is not beneficial in the hospital setting. ${ }^{64,93}$ Subcutaneous epinephrine or terbutaline are options in the acute situation, to provide bronchodilation, but subcutaneous epinephrine has the potential adverse effect of increased heart rate.

The most common systemic corticosteroid during exacerbation treatment in the ED is prednisone. Because comparisons of oral prednisone and intravenous corticosteroids have not shown clinical differences in the rate of lung-function improvement or hospital stay, the oral route is preferred for patients with normal mental status and without conditions expected to interfere with gastrointestinal absorption. ${ }^{94,95}$ Additionally, when considering the dosage of systemic corticosteroids, there are no data to support the use of $>2 \mathrm{mg} / \mathrm{kg}$ per dose, with a maximum of $60 \mathrm{mg}$ for patients $\geq 20 \mathrm{~kg}$. While the ideal dose has not been determined, the asthma guidelines recommend $40-$ $80 \mathrm{mg} / \mathrm{d}$, in either one dose or 2 divided doses. ${ }^{64}$

Non-pharmacologic interventions include ruling out underlying and contributing factors such as rhinovirus infection or pneumonia. An underlying illness can complicate and delay proper management of the asthma exacerbation. When ruling out secondary illnesses, it is common to take into consideration, complete blood count, respiratory syncytial virus test panel, and chest radiograph. It is also very important to find out what controller medication the pa- tient has been using and if they are taking them properly and diligently. That information is integral when determining a discharge plan that works for that patient. After administering albuterol for 1-3 hours and systemic corticosteroids, if the patient's condition has not greatly improved or if an important underlying illness is suspected, it is recommended to admit the patient for further observation and therapy.

A recent paper by Hartman et al concluded that, while fewer children are being admitted with status asthmaticus, the proportion of patients managed in pediatric ICUs is climbing. However, there has been no substantial change in the rates of mechanical ventilation or death in these patients. Additional research is necessary to better comprehend how patients and physicians decide on the appropriate site for hospital care and how that choice affects outcome. ${ }^{96}$

\section{In-Patient Asthma Treatment}

In a patient who requires ICU admission, critical care monitoring and continuous administration of albuterol may be beneficial and is considered a common therapy. The use of 10-20 mg of SABA given over the course of one hour is proven to be acceptable in relieving symptoms in a patient with status asthmaticus. ${ }^{97}$ In the ICU the child should be observed and evaluated every 30 minutes for signs of improvement or deterioration, whereas in a nonICU location the patient should be monitored or assessed at a predetermined interval (eg, every 2 or 3 hours). Monitoring and assessment of oxygenation status should be provided on an established schedule, because patients in severe exacerbation frequently have ventilation/perfusion mismatching and low oxygen saturation.

While bronchodilation is a critical component of inpatient and ICU asthma management, treatment of the underlying inflammatory response and to reduce or prevent hyper-reactivity must be administered concurrently. Steroids, such as prednisone (or solumedrol if intravenous), to target the underlying inflammation should be a component of the hospital treatment regimen. The routine use of ICS in a hospitalized patient has minimal value when compared to systemic corticosteroids.

If the child does not respond to continuous SABA and systemic corticosteroids, intravenous aminophylline may be considered for further bronchodilation, at a loading dosage of $6 \mathrm{mg} / \mathrm{kg}$, followed by age-appropriate dosing $(0.5-1.0 \mathrm{mg} / \mathrm{kg} / \mathrm{h})$. Aminophylline decreases airway inflammation during severe asthma exacerbation, but the aminophylline plasma level must be monitored because the therapeutic range is very limited, and adverse effects are likely. ${ }^{98}$ A Cochrane analysis recommended the addition of intravenous aminophylline to $\beta 2$ agonists and glucocorticoids (with or without anticholinergics), which im- 
proved lung function within 6 hours of treatment, though there was no apparent reduction in symptoms, number of nebulized treatments, or hospital stay. There is insufficient evidence to assess the impact on oxygenation, pediatric ICU admission, or mechanical ventilation. Aminophylline is associated with a substantial risk of vomiting. ${ }^{99}$

Magnesium is another adjunct if the exacerbation fails to respond to the traditional regimen. Magnesium relaxes smooth muscle and thereby relieves asthma symptoms. A recent study by Schuh and colleagues concluded that intravenous magnesium appears to be uncommonly used in stable children with severe acute asthma and does not frequently play a role in reducing hospitalizations. Further research on magnesium is indicated, to establish its adverse-effect profile. ${ }^{100}$ Magnesium is given intravenously, at $50 \mathrm{mg} / \mathrm{kg}$, but the level must be strictly monitored.

Another seldom used adjunct is intravenous terbutaline, which is the current intravenous agent of choice. Intravenous terbutaline is started with a loading dose of $10 \mu \mathrm{g} / \mathrm{kg}$ over $10 \mathrm{~min}$, followed by continuous infusion at $0.1-3 \mu \mathrm{g} /$ $\mathrm{kg} / \mathrm{min}$. The delivery can also be subcutaneous, at $0.01 \mathrm{mg} /$ $\mathrm{kg} / \mathrm{dose}$, with a maximum dose of $0.3 \mathrm{mg}$. The dose may be repeated every $15-20 \mathrm{~min}$ for up to 3 doses. ${ }^{97}$

Heliox has also been successfully utilized in the management of asthma in conjunction with continuous SABA in patients with increased work of breathing, when other therapeutic options have been exhausted. 80/20 heliox may be used in conjunction with continuous SABA to relieve tachypnea and intercostal retractions. If the patient requires supplemental oxygen, additional oxygen may be blended with the heliox, but the use of greater than $35 \%$ oxygen with helium has minimal data to support efficacy in asthma. The patient should also continue receiving other relevant therapies such as fluids and intravenous corticosteroids. A Cochrane analysis found that the existing evidence does not support the use of heliox to all ED patients with acute asthma. Nevertheless, new evidence suggests certain benefits in patients with more severe obstruction. In a review, Frazier and Cheifetz summarized the possible uses of heliox in asthma exacerbation (Table 5). ${ }^{101}$ However, since that information is based on between-group comparisons and small studies, the conclusions are not definitive. ${ }^{102} \mathrm{It}$ is also crucial for the clinician to be able to identify respiratory deterioration and failure, which is uncommon but can occur.

A validated asthma scoring system should be used in assessing asthma exacerbations in children. ${ }^{103}$ Superior to all clinical therapies, a well designed plan of care protocol for all asthma patients will ultimately produce the best results, by decreasing hospital stay, maximizing successful therapies, and minimizing costs. ${ }^{104,105}$ Well devised protocols cover all bases thoroughly and effectively, from initial ED presentation, through in-patient therapy, to education and discharge. The protocol should include eval-
Table 5. Summary of the Clinical Application of Heliox in Asthma Exacerbation

Heliox may benefit initial treatment of pediatric asthma, serving as a bridge until corticosteroids have clinical effect.

Heliox benefits initial treatment of moderate to severe asthma exacerbation in the emergency department.

Heliox is most beneficial in the initial treatment period; clinical improvement with heliox, as compared to oxygen-enriched air, becomes less evident over time.

Heliox appears to improve gas exchange in patients with asthma to require intubation, potentially decreasing the ventilator support required.

Heliox allows lower ventilator settings and lower $\mathrm{F}_{\mathrm{IO}_{2}}$, decreasing the risk of ventilator-induced lung injury.

With the increasing use of noninvasive ventilation, the role of heliox as an adjunctive therapy could be further evaluated in the intensive care setting.

(Adapted from Reference 101.)

uation components that can monitor, through some quality-assurance mechanism, the success and failure of the instrument, so that modifications can be made as necessary. ${ }^{106}$ The protocol should be strictly monitored for adherence and relevance in an evidenced-based fashion at all times, for consistent and optimal results.

\section{Education}

Asthma self-management education encompasses a collaborative partnership between the clinician, the patient, and the patient's caregiver. Asthma management should promptly begin when a patient is initially diagnosed or when the newly diagnosed patient is planning to be discharged. Successful ambulatory care and management is paramount to the control of asthma. Kwong and colleagues demonstrated that achieving and maintaining asthma control in inner-city children substantially reduced asthmarelated morbidity, and systematic assessment of asthma control may help predict future risk in children with asthma. ${ }^{107}$

Haselkorn and colleagues recently studied the association between uncontrolled asthma and activity limitations, in a nationally representative sample of patients with moderate to severe treated asthma, to assess the degree to which demographics and comorbidities are associated with activity limitations. Compared to the patients with controlled asthma, the patients with uncontrolled asthma were at higher risk for limitations in outdoor activity, physical activity, and daily activity. To help patients achieve optimal health, asthma management should include routine assessment of activity limitations and assessment of and coordinated care for comorbid conditions. ${ }^{108}$

The scientific evidence on written asthma treatment plans is inconclusive. A Cochrane review stated there is not 
enough evidence to show that personalized, written asthma self-management plans, as the sole intervention, improve outcomes; however, providing clear written instructions to patients is good clinical practice. ${ }^{109} \mathrm{~A}$ written asthma action plan is the most appropriate method to provide concise instructions on managing ambulatory asthma symptoms and exacerbations.

This written plan should include relevant information regarding triggers, medications, and emergency contacts. The patient should be familiar with and able to use a peak flow meter, and to know his or her personal best peak flow. When identifying triggers it is important to consider the patient's home life and what the child may be exposed to on a daily basis. Understanding what led to the most recent exacerbation can also help pinpoint what factors could be contributing. The child should then be instructed to avoid or eliminate the trigger.

Medications should be discussed at every clinical visit, with a review of the roles of the medications in asthma management and verification of correct delivery technique. Deis and colleagues found that parents of children with persistent asthma presenting to urban tertiary-care pediatric EDs with asthma exacerbation frequently have inadequate understanding of appropriate ICS use, and those with less than a high school education, in particular, may benefit from focused educational interventions that address the importance of daily ICS use in asthma control. Parents who receive a written action plan are more confident in their ability to provide care for their child during an asthma exacerbation. ${ }^{110}$ If seen in an acute care setting, the patient should be sent home with prescriptions for a controller medication and a rescue SABA inhaler. A VHC is also a key factor in optimizing the efficacy of MDI medications.

A study of baseline data from the School-Based Asthma Therapy trial, which is an ongoing comprehensive schoolbased intervention for urban children, documented that assisting families to develop routines around asthma care might improve preventive care for urban youth. ${ }^{111}$ Similarly, a Cochrane analysis found that some evidence from 2 trials of family therapy (in addition to standard asthma treatments) might help reduce a child's asthma symptoms, but more research is needed to be certain. ${ }^{112}$

In another recent trial, Cloutier and Wakefield sought to determine if a successful asthma-management program could be translated into pediatricians' offices, improve care, and reduce medical services use. ${ }^{113}$ The data from over 10,000 children in Connecticut (about $40 \%$ on Medicaid) demonstrated that general pediatricians could successfully implement the asthma-management program and that it improved care for large numbers of children. A key ingredient in the successful management and control of asthma is future interventions that will document real-world suc- cesses that are translated to a larger portion of the population at risk.

A Cochrane analysis concluded that asthma self-management education programs for children improve several outcomes, and that self-management education directed toward prevention and management of attacks should be incorporated into routine asthma care. Conclusions about the effectiveness of the various components are limited by a lack of direct comparisons. Future trials of asthma-education programs should focus on morbidity and functional status outcomes, including quality of life, and involve direct comparisons of the various components of the interventions. ${ }^{114}$ New strategies that promote patient adherence to therapy and that are broadly generalizable, low-cost, and sustainable are desperately needed.

A study by Edgecombe et al of adolescents with uncontrolled severe asthma, provided the following key messages. Most adolescents do not take their inhaled medication with the spacer device (an example of intentional non-adherence), and most do not take responsibility for their asthma or interact with health professionals, but instead rely on their parents to communicate with clinicians. ${ }^{115}$ A study by Cohn and colleagues stated that a relationship seems to exist between treatment adherence and the type of medication delivery system used in childhood asthma, and that the highest adherence is associated with oral medications. Based on a literature review, Cohn et al concluded that clinicians should consider the medication delivery mode as one factor that can influence adherence. ${ }^{116}$

Improving patient adherence to therapy is a key component of self-management, regardless of the disease etiology. Adherence to asthma medications is essential for achieving asthma control and avoiding exacerbations. Changing adherence behavior is difficult, and education alone is not enough. Successful interventions are multifactorial. Recent intervention strategies that have shown some promise include improved patient-provider communication, simplifying therapy, interventions to improve motivation, monitoring of and feedback about adherence, and shared-decision making.

\section{Summary}

While asthma management and treatment have made huge strides over the past few decades, many questions remain regarding epidemiology, pathophysiology, environmental control, disparities in care, diagnosis, assessment, monitoring, pharmacology, exacerbation management, and education, and many great mysteries have yet to be solved. The focus has shifted from exacerbation management to long-term disease management and control.

While asthma medications have become more efficient and effective, getting them to those in need and ensuring 
their correct use and delivery face many challenges and pitfalls. While mortality, ED visits, and hospitalizations have plateaued or declined, the prevalence and daily morbidity of pediatric asthma continue to increase across all communities and place a heavy burden on those with socioeconomic disparities.

As with any successful endeavor, key strategies and vision toward the future are paramount to moving forward. The management and treatment of asthma in children must continue to move forward, or we shall fall behind what some have termed an epidemic. With that being said, the following 3 areas are key focal points as we move forward over the next decade in our pursuit of optimal asthma management and treatment.

\section{A Need for Standardization and Collaboration}

- The development and call for scientific projects and strategies that produce well designed studies of pediatric asthma that assess cost/benefit ratio, employing evidenced-based approaches, and stressing the importance of more appropriate asthma treatment models of care

- The development of a comprehensive approach to standardize outcome measures to permit comparisons across studies and clinical trials between different investigators

\section{Conceptualization and Development of Performance- Based Models}

- With healthcare reform focusing on prevention and wellness models, a focus on incentivized approaches between healthcare financing to quality and outcomes

- Multifaceted approaches in a disease-management model to study the effect of performance-based care on closing the gap on evidence-based clinical care

- United States healthcare reform rests in part on our ability to implement quality performance metrics for chronic conditions and the elimination of health disparities

\section{Evidence-Based Interventions}

- A multifactorial disease with increasing prevalence necessitates that asthma care be conducted on evidencedbased management principles

- Wider dissemination and implementation of evidencebased interventions that tailor care to individual risks and sensitivities, as well as to community-wide characteristics, must be investigated and deployed successfully across the continuum of care to ensure high standards of asthma care

- Further research to gain a better understanding of treatment being multi-phased and multi-faceted with variable outcomes in the ambulatory and acute care settings
- Better knowledge and dissemination of education, adherence, and behavior interventions for asthma selfmanagement

- Research into how ethnicities, sex, and age, as well as other disparities of certain groups, have effects on asthma and the response to asthma treatment (medications, perception, and environmental control, for example)

- Differences in response to treatment in different severities of asthma have yet to be explored

- Therapeutics also needs to be studied in relationship to genetic factors (ie, pharmacogenetics)

- Research that addresses asthma prevention, disease modification, and reversal of underlying mechanisms, is of particular need and importance.

\section{REFERENCES}

1. Lurie N, Mitchell HE, Malveaux FJ. State of childhood asthma and future directions conference: overview and commentary. Pediatrics 2009;123(Suppl 3):S211-S214.

2. Akinbami LJ, Moorman JE, Garbe PL, Sondik EJ. Status of childhood asthma in the United States, 1980-2007. Pediatrics 2009; 123(Suppl 3):S131-S145.

3. Mannino DM, Homa DM, Akinbami LJ, Moorman JE, Gwynn C, Redd SC. Surveillance for asthma: United States, 1980-1999. MMWR Surveill Summ 2002;51(1):1-13.

4. Centers for Disease Control and Prevention. 2007 National Health Interview Survey (NHIS) Data. Table 1-1. Lifetime asthma population estimates, in thousands, by age, United States: National Health Interview Survey, 2007. Compiled September 19, 2008. http://www. cdc.gov/asthma/nhis/07/table1-1.htm. Accessed July 12, 2011.

5. Centers for Disease Control and Prevention. National Health Interview Survey 2007 data release. http://www.cdc.gov/NCHS/nhis/ nhis_2007_data_release.htm. Accessed July 12, 2011.

6. Centers for Disease Control and Prevention. 2007 National Health. Interview Survey (NHIS) Data. Table 4-1. Current asthma prevalence percents by age, United States: National Health Interview Survey, 2007. http://www.cdc.gov/asthma/nhis/07/table4-1.htm. Accessed July 12, 2011.

7. Hing E, Cherry DK, Woodwell DA. National Ambulatory Medical Care Survey: 2004. Advance data from vital and health statistics; no 374. National Center for Health Statistics; 2006.

8. Akinbami LJ, Moorman JE, Garbe PL, Sondik EJ. Status of childhood asthma in the United States, 1980-2007. Pediatrics 2009; 123(Suppl 3):S131-S145.

9. DeFrances CJ, Podgornik MN. 2004 National Hospital Discharge Survey. Advance data from vital and health statistics; no 371. Hyattsville, MD: National Center for Health Statistics; 2006.

10. Hartman ME, Linde-Zwirble WT, Angus DC, Watson RS. Trends in admissions for pediatric status asthmaticus in New Jersey over a 15-year period. Pediatrics 2010;126(4):e904-e911.

11. McFadden ER Jr, Warren EL. Observations on asthma mortality. Ann Intern Med 1997;127(2):142-147.

12. Gergen PJ, Mullally DI, Evans R III. National survey of prevalence of asthma among children in the United States, 1976 to 1980. Pediatrics 1988;81(1):1-7.

13. Spycher BD, Silverman M, Kuehni CE. Phenotypes of childhood asthma: are they real? Clin Exp Allergy 2010;40(8):1130-1141. 
14. Valerio MA, Andreski PM, Schoeni RF, McGonagle KA. Examining the association between childhood asthma and parent and grandparent asthma status: implications for practice. Clin Pediatr (Phila) 2010;49(6):535-541.

15. Berg AO, Baird MA, Botkin JR Driscoll DA, Fishman PA, Guarino PD et al. National Institutes of Health State-of-the-Science Conference Statement. Family history and improving health. Ann Intern Med 2009;151(12):872-877.

16. Yang KD. Consensus: limitations and perspectives on pediatric asthma treatment. Pediatr Neonatol 2010;51(1):5-6.

17. Ober C, Hoffjan S. Asthma genetics 2006: the long and winding road to gene discovery. Genes Immun 2006;7(2):95-100.

18. Bisgaard H, Bønnelykke K. Long-term studies of the natural history of asthma in childhood. J Allergy Clin Immunol 2010;126(2):18797.

19. Strachan DP. Family size, infection and atopy: the first decade of "hygiene hypothesis". Thorax 2000;55(Suppl I):2-10.

20. Strachan DP, Cook DG. Health effects of passive smoking. 5. Parental smoking and allergic sensitization in children. Thorax 1998; 53(2):117-123.

21. Strachan DP, Cook DG. Health effects of passive smoking. 6. Parental smoking and childhood asthma: longitudinal and case-control studies. Thorax 1998;53(3):204-212.

22. Bisgaard H, Loland L, Holst KK, Pipper CB. Prenatal determinants of neonatal lung function in high-risk newborns. J Allergy Clin Immunol 2009;123(3):651-657, e1-e4.

23. Stein RT, Holberg CJ, Sherrill D, Wright AL, Morgan WJ, Taussig $\mathrm{L}$, et al. Influence of parental smoking on respiratory symptoms during the first decade of life: the Tucson Children's Respiratory Study. Am J Epidemiol 1999;149(11):1030-1037.

24. Arshad SH, Kurukulaaratchy RJ, Fenn M, Matthews S. Early life risk factors for current wheeze, asthma, and bronchial hyperresponsiveness at 10 years of age. Chest 2005;127(2):502-508.

25. Wilson SR, Farber HJ, Knowles SB, Lavori PW. A randomized trial of parental behavioral counseling and cotinine feedback for lowering environmental tobacco smoke exposure of children with asthma: results of the LET'S Manage Asthma trial. Chest 2011; 139(3):581-590.

26. Ashley MJ, Ferrence R. Reducing children's exposure to environmental tobacco smoke in homes: issues and strategies. Tob Control 1998;7(1):61-65.

27. Mackay D, Haw S, Ayres JG, Fischbacher C, Pell JP. Smoke-free legislation and hospitalizations for childhood asthma. N Engl J Med 2010;363(12):1139-1145.

28. American Thoracic Society. What constitutes an adverse health effect of air pollution? Official statement of the American Thoracic Society. Am J Respir Crit Care Med 2000;161(2 Pt 1):665-673.

29. McConnell R, Berhane K, Gilliland F, London SJ, Islam T, Gauderman WJ, Avol E, Margolis HG, Peters JM. Asthma in exercising children exposed to ozone: a cohort study. Lancet 2002;359(9304): 386-391.

30. Urbano FL. Review of the NAEPP 2007 Expert Panel Report (EPR-3) on asthma diagnosis and treatment guidelines. J Manag Care Pharm 2008;14(1):41-49.

31. Leickly FE. Children, their school environment, and asthma. Ann Allergy Asthma Immunol 2003;90(1):3-5.

32. Lupoli TA, Ciaccio CE, Portnoy JM. Home and school environmental assessment and remediation. Curr Allergy Asthma Rep 2009; 9(6):419-425.

33. Sheehan WJ, Rangsithienchai PA, Baxi SN, Gardynski A, Bharmanee A, Israel E, Phipatanakul W. Age-specific prevalence of outdoor and indoor aeroallergen sensitization in Boston. Clin Pediatr (Phila) 2010;49(6):579-585.
34. Morgan WJ, Crain EF, Gruchalla RS, O'Connor GT, Kattan M, Evans R 3rd et al. Results of a home-based environmental intervention among urban children with asthma. N Engl J Med 2004; 351(11):1068-1080.

35. Kilpatrick N, Frumkin H, Trowbridge J, Escoffery C, Geller R, Rubin I, et al. The environmental history in pediatric practice: a study of pediatricians' attitudes, beliefs, and practices. Environ Health Perspect 2002;110(8):823-827.

36. Sigurs N, Bjarnason R, Sigurbergsson F, Kjellman B. Respiratory syncytial virus bronchiolitis in infancy is an important risk factor for asthma and allergy at age 7. Am J Respir Crit Care Med 2000; 161(5):1501-1507.

37. Ogden CL, Carroll MD, Curtin LR, McDowell MA, Tabak CJ, Flegal KM. Prevalence of overweight and obesity in the United States, 1999-2004. JAMA 2006;295(13):1549-1555.

38. Ford ES. The epidemiology of obesity and asthma. J Allergy Clin Immunol 2005;115(5):897-909.

39. Story RE. Asthma and obesity in children. Curr Opin Pediatr 2007; 19(6):680-684.

40. Ginde AA, Santillan AA, Clark S, Camargo CA Jr. Body mass index and acute asthma severity among children presenting to the emergency department. Pediatr Allergy Immunol 2010;21(3):480488.

41. Piper CN, Glover S, Elder K, Baek JD, Wilkinson L. Disparities in access to care among asthmatic children in relation to race and socioeconomic status. J Child Health Care 2010;14(3):271-279.

42. Kogan MD, Newacheck PW, Blumberg SJ, Ghandour RM, Singh GK, Strickland BB, van Dyck PC. Underinsurance among children in the United States. N Engl J Med 2010;363(9):841-851.

43. Stewart KA, Higgins PC, McLaughlin CG, Williams TV, Granger E, Croghan TW. Differences in prevalence, treatment, and outcomes of asthma among a diverse population of children with equal access to care: findings from a study in the military health system. Arch Pediatr Adolesc Med 2010;164(8):720-726.

44. Dombkowski KJ, Hassan F, Wasilevich EA, Clark SJ. Spirometry use among primary pediatric care physicians. Pediatrics 2010;126(4): 682-687.

45. Beydon N, Davis SD, Lombardi E, Allen JL, Arets HG, Aurora P et al. An official American Thoracic Society/European Respiratory Society statement: pulmonary function testing in preschool children. Am J Respir Crit Care Med 2007;175(12):1304-1345.

46. Stocks J. Clinical implications of pulmonary function testing in preschool children. Paediatric Respir Rev2006;7(Suppl 1):S26-S29.

47. Smith AD, Cowan JO, Brassett KP, Filsell S, McLachlan C, MontiSheehan $\mathrm{G}$ et al. Exhaled nitric oxide: a predictor of steroid response. Am J Respir Crit Care Med 2005;172(4):453-459.

48. Caudri D, Wijga AH, Hoekstra MO, Kerkhof M, Koppelman GH, Brunekreef B, et al. Prediction of asthma in symptomatic preschool children using exhaled nitric oxide, Rint and specific IgE. Thorax 2010;65(9):801-807.

49. Zacharasiewicz A. Fractional exhaled nitric oxide and induced sputum. Paediatric Respir Rev 2007;8(1):94-96.

50. Petsky HL, Cates CJ, Li A, Kynaston JA, Turner C, Chang AB. Tailored interventions based on exhaled nitric oxide versus clinical symptoms for asthma in children and adults. Cochrane Database Syst Rev 2009;(4):CD006340.

51. Beck R, Elias N, Shoval S, Tov N, Talmon G, Godfrey S, Bentur L. Computerized acoustic assessment of treatment efficacy of nebulized epinephrine and albuterol in RSV bronchiolitis. BMC Pediatr 2007; 7:22-27.

52. Bentur L, Beck R, Berkowitz D, Hasanin J, Berger I, Elias N, Gavriely N. Adenosine bronchial provocation with computerized wheeze detection in young infants with prolonged cough. Chest 2004;126(4):1060-1065. 
53. Prodhan P, Dela Rosa RS, Shubina M, Haver KE, Matthews BD, Buck S, et al. Wheeze detection in the pediatric intensive care unit: comparison among physician, nurses, respiratory therapists, and a computerized respiratory sound monitor. Respir Care 2008;53(10): 1304-1309.

54. Horsley A. Lung clearance index in the assessment of airways disease. Respir Med 2009;103(6):793-799.

55. Aurora P, Kozlowska W, Stocks J. Gas mixing efficiency from birth to adulthood measured by multiple-breath washout. Respir Physiol Neurobiol 2005;148(1-2):125-139.

56. Bateman ED, Bousquet J, Keech ML, Busse WW, Clark TJ, Pedersen SE. The correlation between asthma control and health status: the GOAL study. Eur Respir J 2007;29(1):56-62.

57. Pedersen SE, Bateman ED, Bousquet J, Busse WW, Yoxall S, Clark TJ. Determinants of response to fluticasone propionate and salmeterol/fluticasone propionate combination in the Gaining Optimal Asthma control study. J Allergy Clin Immunol 2007;120(5): 1036-1042.

58. Pedersen S. From asthma severity to control: a shift in clinical practice. Prim Care Respir J 2010;19(1):3-9.

59. Sorkness CA. Traditional and new approaches to asthma monitoring. Respir Care 2008;53(5):593-599; discussion 599-601.

60. Andersson M, Bjerg A, Forsberg B, Lundback B, Ronmark E. The clinical expression of asthma in schoolchildren has changed between 1996-2006. Pediatr Allergy Immunol 2010;21(5):859866.

61. Barnes PJ. Drugs for asthma. Br J Pharmacol 2006;147(Suppl 1): S297-S303.

62. Lipworth BJ, Struthers AD, McDevitt DG. Tachyphylaxis to systemic but not to airway responses during prolonged therapy with high dose inhaled salbutamol in asthmatics. Am Rev Respir Dis 1989;140(3):586-592.

63. Repsher LH, Anderson JA, Bush RK, Falliers CJ, Kass I, Kemp JP et al. Assessment of tachyphylaxis following prolonged therapy of asthma with inhaled albuterol aerosol. Chest 1984;85(1): 34-38.

64. National Heart, Lung, and Blood Institute, National Asthma Education and Prevention Program. Expert panel report 3: guidelines for the diagnosis and management of asthma. Bethesda, MD: National Heart, Lung, and Blood Institute; revised August 2007. NIH publication no. 07-4051.

65. Lawford P, McKenzie D. Pressurized aerosol inhaler technique: how important are inhalation from residual volume, inspiratory flow rate and the time interval between puffs? Br J Dis Chest 1983;77(3):276-281.

66. Rebuck AS, Chapman KR, Abboud R, Pare PD, Kreisman H, Wolkove $\mathrm{N}$ et al. Nebulized anticholinergic and sympathomimetic treatment of asthma and chronic obstructive airways disease in the emergency room. Am J Med 1987;82(1):59-64.

67. O'Driscoll BR, Kalra S, Wilson M, Pickering CA, Carroll KB, Woodcock AA. Double-blind trial of steroid tapering in acute asthma. Lancet 1993;341(8841):324-327.

68. Elward KS, Pollart SM. Medical therapy for asthma: updates from the NAEPP Guidelines. Am Fam Physician 2010;82(10):1242-1251.

69. Lipworth BJ, Sims EJ, Das SK, Morice AH, O'Connor BJ. Bronchoprotection with formoterol via dry powder and metered-dose inhalers in patients with asthma. Ann Allergy Asthma Immunol 2005;95(3):283-290.

70. Leach CL, Davidson PJ, Hasselquist BE, Boudreau RJ. Lung deposition of hydrofluoroalkane-134a beclomethasone is greater than that of chlorofluorocarbon fluticasone and chlorofluorocarbon beclomethasone: a crossover study in healthy volunteers. Chest 2002; 122(2):510-516.
71. Powell H, Gibson PG. High dose versus low dose inhaled corticosteroid as initial starting dose for asthma in adults and children. Cochrane Database Syst Rev 2004;(2):CD001409.

72. Zhang L, Axelsson I, Chung M, Lau J. Dose response of inhaled corticosteroids in children with persistent asthma: a systematic review. Pediatrics 2011;127(1):129-138.

73. Nelson JA, Strauss L, Skowronski M, Ciufo R, Novak R, McFadden ER Jr. Effect of long-term salmeterol treatment on exerciseinduced asthma. N Engl J Med 1998;339(3):141-146.

74. Simons FE, Gerstner TV, Cheang MS. Tolerance to the bronchoprotective effect of salmeterol in adolescents with exercise-induced asthma using concurrent inhaled glucocorticoid treatment. Pediatrics 1997;99(5):655-659.

75. Nelson HS, Weiss ST, Bleecker ER, Yancey SW, Dorinsky PM; SMART Study Group. The Salmeterol Multicenter Asthma Research Trial: a comparison of usual pharmacotherapy for asthma or usual pharmacotherapy plus salmeterol Chest 2006;129(1):15-26. Erratum in: Chest 2006;129(5):1393.

76. Eid NS, Noonan MJ, Chipps B et al. Once- vs. twice-daily budesonide/formoterol in 6- to 15-year-old patients with stable asthma. Pediatrics 2010;126(3):e565-e575.

77. Ostrom NK, Decotiis BA, Lincourt WR, et al. Comparative efficacy and safety of low-dose fluticasone propionate and montelukast in children with persistent asthma. J Pediatr 2005;147(2): 213-220.

78. Jat GC, Mathew JL, Singh M. Treatment with 400 microg of inhaled budesonide versus 200 microg of inhaled budesonide and oral montelukast in children with moderate persistent asthma: randomized controlled trial. Ann Allergy Asthma Immunol 2006;97(3): 397-401.

79. Joos S, Miksch A, Szecsenyi J, Wiseler B, Grouven U, Kaiser T, Schneider A. Montelukast as add-on therapy to inhaled corticosteroids in the treatment of mild to moderate asthma: a systematic review. Thorax 2008;63(5):453-462.

80. Virchow JC, Mehta A, Ljungblad L, Mitfessel H; MONICA Study Group. Add-on montelukast in inadequately controlled asthma patients in a 6-month open-label study: the MONtelukast In Chronic Asthma (MONICA) study. Respir Med 2010;104(5):644-651.

81. Barnes PJ. Scientific rationale for combination inhalers with a longacting beta2-agonists and corticosteroids. Eur Respir J 2002;19(1): 182-191.

82. Lodrup Carlsen KC, Devulapalli CS, Mowinckel P, Haland G, Munthe-Kaas MC, Carlsen KH. Lung function at 10 yrs. is not improved by early corticosteroid treatment in asthmatic children. Pediatr Allergy Immunol 2010;21(5):814-822.

83. Barnes PJ. New drugs for asthma. Nat Rev Drug Discov 2004; 3(10):831-844.

84. Barnes P. New therapies for asthma: is there any progress? Trends Pharmacol Sci 2010;31(7):335-343.

85. Fink JB, Rubin BK. Problems with inhaler use: a call for improved clinician and patient education. Respir Care 2005;50(10): 1360-1374; discussion 1374-1375.

86. Brocklebank D, Ram F, Wright J, Barry P, Cates C, Davies L, et al. Comparison of the effectiveness of inhaler devices in asthma and chronic obstructive airways disease: a systematic review of the literature. Health Technol Assess 2001;5(26):1-149.

87. Welch MJ, Martin ML, Williams PV, et al. evaluation of inhaler device technique in caregivers of young children with asthma. Pediatr Allergy Immunonol Pulm 2010;23(2):1-8.

88. Mitchell JP, Nagel MW. Valved Holding Chambers (VHCs) for use with pressurized metered dose inhalers (pMDIs): a review of causes of inconsistent medication delivery. Prim Care Respir J 2007;16(4): $7-14$. 
89. Rau JL. The inhalation of drugs: advantages and problems. Respir Care 2005;50(3):367-382.

90. Schultz A, Le Souëf TJ, Venter A, Devadason SG. Le Souëf PN. Aerosol inhalation from spacers and valved holding chambers requires few tidal breaths for children. Pediatrics 2010;126(6):e1493e1498.

91. Lazarus SC. Emergency treatment of asthma. N Engl J Med 2010; 363(8):755-764.

92. Rodrigo GJ, Castro-Rodriguez JA. Anticholinergics in the treatment of children and adults with acute asthma: a systematic review with meta-analysis. Thorax 2005;60(9):740-746.

93. Craven D, Kercsmar CM, Myers TR, O'Riordan MA Golonka G, Moore S. Ipratropium bromide plus nebulized albuterol for the treatment of hospitalized children with acute asthma. J Pediatr 2001; 138(2):51-58.

94. Ratto D, Alfaro C, Sipsey J, Glovsky MM, Sharma OP. Are intravenous corticosteroids required in status asthmaticus? JAMA 1988; 260(4):527-529.

95. Barnett PL, Caputo GL, Baskin M, Kuppermann N. Intravenous versus oral corticosteroids in the management of acute asthma in children. Ann Emerg Med 1997;29(2):212-217.

96. Hartman ME, Linde-Zwirble WT, Angus DC, Watson RS. Trends in admissions for pediatric status asthmaticus in New Jersey over a 15-year period. Pediatrics 2010;126(4):e904-e911.

97. Saharan S, Lodha R, Kabra SK. Management of status asthmaticus in children. Indian J Pediatr 2010;77(12):1417-1422.

98. Lebovitz DJ, Smith PG, O'Riordan MA, Reed MD. Pharmacokinetic properties and tolerability of single-dose terbutaline in patients with severe asthma treated in the pediatric intensive care unit. Curr Ther Res Clin Exp 2004;65:98-109.

99. Mitra AAD, BasslerD, Watts K, Lasserson TJ, Ducharme FM. Intravenous aminophylline for acute severe asthma in children over two years receiving inhaled bronchodilators. Cochrane Database Syst Rev 2005;(2):CD001276.

100. Schuh S, Macias C, Freedman SB, Plint AC, Zorc JJ, Bijal L, et al. North American practice patterns of intravenous magnesium therapy in severe acute asthma in children. Acad Emerg Med 2010; 17(11):1189-1196

101. Frazier MD, Cheifetz IR. The role of heliox in paediatric respiratory disease. Paediatr Respir Rev 2010;11(1):46-53.

102. Rodrigo GJ, Pollack CV, Rodrigo C, Rowe BH. Heliox for nonintubated acute asthma patients. Cochrane Database Syst Rev 2006; (4):CD002884.
103. Gouin S, Robidas I, Gravel J, Guimont C, Chalut D, Amre D. Prospective evaluation of two clinical scores for acute asthma in children 18 months to 7 years of age. Acad Emerg Med 2010;17(6): 598-603.

104. McDowell KM, Chatburn RL, Myers TR, O'Riordan MA, and Kercsmar CM. A cost effective algorithm for children hospitalized for status asthmaticus. Arch Pediatr Adolesc Med 1998;152(10): 977-984

105. Myers TR, Chatburn RL, Kercsmar CM. A pediatric asthma unit staffed by respiratory therapists demonstrates positive clinical and financial outcomes. Respir Care 1998;43(1):22-29.

106. Myers TR. The value of care algorithms. Pharmacotherapy 2006; 26(9 Part 2):S181-S192.

107. Kwong KY, Morphew T, Scott L, Guterman J, Jones CA. Asthma control and future asthma-related morbidity in inner-city asthmatic children. Ann Allergy Asthma Immunol 2008;101(2):144152.

108. Haselkorn T, Chen H, Miller DP, Fish JE, Peters SP, Weiss S, et al. Asthma control and activity limitations: insights from the Realworld Evaluation of Asthma Control and Treatment (REACT) Study. Ann Allergy Asthma Immunol 2010;104(6):471-477.

109. Toelle B, Ram FSF. Written individualized management plans for asthma in children and adults. Cochrane Database Syst Rev 2004; (1):CD002171.

110. Deis JN, Spiro DM, Jenkins CA, Buckles TL, Arnold DH. Parental knowledge and use of preventive asthma care measures in two pediatric emergency departments. J Asthma 2010;47(5):551556.

111. Peterson-Sweeney K, Halterman JS, Conn K, Yoos HL. The effect of family routines on care for inner city children with asthma. J Pediatr Nurs 2010;25(5):344-351.

112. Yorke J, Shuldham C. Family therapy for asthma in children. Cochrane Database Syst Rev 2005;(2):CD000089.

113. Cloutier MM, Wakefield DB. Translation of a pediatric asthmamanagement program into a community in Connecticut. Pediatrics 2011;127(1):11-18.

114. Wolf F, Guevara JP, Grum CM, Clark NM, Cates CJ. Educational interventions for asthma in children. Cochrane Database Syst Rev 2003;(1):CD000326.

115. Edgecombe K, Latter S, Peters S, Roberts G. Health experiences of adolescents with uncontrolled severe asthma. Arch Dis Child 2010; 95(12):985-991.

116. Cohn RC. Systems on treatment adherence in children with asthma. Curr Ther Res Clin Exp 2003;64:34-44.

\section{Discussion}

Phelan:* Has anyone researched the impact of anti-smoking legislation? Are there any economics data, from a consumption standpoint?

Myers: There was a study ${ }^{1}$ that did not get a lot of play in the media or in the literature. I think we're seeing an-

\footnotetext{
* Bill Phelan RRT-NPS, GE Healthcare, Waukesha, Wisconsin.
}

ti-smoking legislation becoming more and more aggressive. It started in indoor environments and now there are places looking at laws that prohibit smoking on the sidewalk or any public environment. We know it's a very prevalent exacerbation risk, even in infants born to smoking mothers: they have a higher prevalence of asthma and respiratory disorders than children born to non-smoking moms. ${ }^{2,3}$ It's just a question of getting that message out and showing the benefits from reducing secondhand smoke exposure, as opposed to the concentration on primary smokers that we've seen recently.

1. Mackay D, Haw S, Ayres JG, Fischbacher C, Pell JP. Smoke-free legislation and hospitalizations for childhood asthma. N Engl J Med 2010;363(12):1139-1145.

2. Cohen RT, Raby BA, Van Steen K, Fuhlbrigge AL, Celedón JC, Rosner BA, et al; Childhood Asthma Management Program Research Group. In utero smoke exposure and impaired response to inhaled corticosteroids in children with asthma. J Allergy Clin Immunol 2010;126(3):491-497.

3. Wang C, Salam MT, Islam T, Wenten M, Gauderman WJ, Gilliland FD. Effects of in 
utero and childhood tobacco smoke exposure and $\beta_{2}$ adrenergic receptor genotype on childhood asthma and wheezing. Pediatrics 2009;122(1):e107-e114.

Cheifetz: In the in-patient setting we frequently discuss the need for referral to a subspecialist prior to hospital discharge, and which patients who were admitted with status asthmaticus require referral to a subspecialist. Should the trigger be an ICU admission? Or a recurrent admission? Any admission? Recurrent ED presentation? Which child with asthma requires referral to a subspecialist?

Myers: Fuhlbrigge studied a pediatric population and showed that, no matter how well controlled your asthma is, about $25-33 \%$ of the patient population will have an exacerbation within the next year, ${ }^{1}$ so I don't think exacerbation is the hallmark for referral to a specialist. I think a child who comes into the ED and gets hospitalized-and definitely anybody in the ICU-should be referred to a specialist. If you look at the scoring of intermittent asthma and then mild, moderate, and severe persistent asthma-I think when you get to moderate persistent, and they're using multiple controller drugs, those patients should definitely get referred to a specialist as well.

1. Fuhlbrigge AL, Kitch BT, Paltiel AD, Kuntz KM, Neumann PJ, Dockery DW, Weiss ST. $\mathrm{FEV}_{1}$ is associated with risk of asthma attacks in a pediatric population. J Allergy Clin Immunol 2001;107(1):61-67.

Willson: The prevalence of asthma in African Americans in the United States is much higher than in the white population. I go to Haiti on a regular basis, and have for 15 years, and, historically, Haiti has the same black population as the United States, but I think that in 15 years I have seen only a handful of Haitian kids with wheezing. Does that agree with the hygiene hypothesis?

Myers: That's interesting, because there may be some genetic similari- ties there, but there's obviously something from a genetic standpoint that is different. We know that in a place like Haiti the socioeconomic status probably isn't much better than some components that have a high prevalence of asthma in the United States, so that leads it back to not only a genetic component but a hygiene or environment component. If they're genetically predisposed and sensitized at a very early age to those markers that trigger and cause repeated inflammatory mediators, they may end up with a much higher prevalence.

There are some data on Puerto Ricans who were born in Puerto Rico versus born in the United States, and there's a huge disparity in their asthma prevalence and severity as well, which disfavors the United-States-born people. ${ }^{1}$ There's something about the environment of industrialized nations, which have a high prevalence of asthma: the United States, Canada, the United Kingdom, and Australia. Places that we typically think of as industrialized nations probably have a lot of environmental factors that play a huge role in the development of asthma.

1. Esteban CA, Klein RB, McQuaid EL, Fritz GK, Seifer R, Kopel SJ, et al. Conundrums in childhood asthma severity, control, and health care use: Puerto Rico versus Rhode Island. J Allergy Clin Immunol 2009; 124(2):238-244.

Rubin: There's another factor, to answer, which is the over-diagnosis of asthma, particularly in the youngest of children. It's been shown that asthma is over-diagnosed in about $30 \%$ of the population. ${ }^{1}$ Longitudinal studies suggest that in children under age 3 as many as $60 \%$ of wheezy infants who are diagnosed with asthma may not have it at all. They don't have recurrent multi-trigger wheezing that's amenable to therapy. It may be that if you have a hammer, everything looks like a nail. Since we have treatments that work for asthma but not for many other things (other than telling parents they shouldn't smoke), we tend to use them. There are a lot of patients on too many medicines, on too much asthma care, who may not have asthma at all.

1. Luks VP, Vandemheen KL, Aaron SD. Confirmation of asthma in an era of overdiagnosis. Eur Respir J 2010;36(2):255260.

Myers: That points to the importance not only of early diagnosis and whether to treat those patients, but also to continual assessment and monitoring. That goes back to Ira's [Cheifetz] comment that primary care doesn't have the necessary resources. The proceedings ${ }^{1}$ from the second of the AARC [American Association for Respiratory Care] "2015 and Beyond" conferences really push respiratory therapists as disease managers who have the diagnosis, assessment, and monitoring skills. If we can get the respiratory therapists out into the ambulatory out-patient clinic setting, we may be able to facilitate appropriate diagnosis, monitoring, and treatment, or reveal the lack thereof, as you point out. But we can't get there if we don't change the healthcare vehicle and the way care is reimbursed, because nobody's going to pay for respiratory therapists to be in their offices without reimbursement. That relates to the AARC's Medicare Part B initiative.

1. Barnes TA, Gale DD, Kacmarek RM, Kageler WV. Competencies needed by graduate respiratory therapists in 2015 and beyond. Respir Care 2010;55(5):601-616.

Willson: I wasn't completely honest in my question. We've known for years that kids who live on farms have a much lower incidence of asthma than kids who are raised in cities. I wonder if it isn't actually exposure to parasites for the kids in Haiti that changes their immune response and leads to a much lower incidence of asthma. It may explain some of this. I'm not suggesting we expose little kids to parasites, but there may be a clue there to help us decrease the high incidence in 
industrialized nations. We may actually be too clean.

Myers: I agree, and there has been some research on that. In some countries that aren't as developed, the prevalence of asthma is lower, despite a heavy exposure to triggers and allergens; they're sensitized, but it doesn't trigger that immune response. There is something present from a genetic versus environment perspective in some cases that leads to sensitization and an allergen activating a chronic inflammatory response and the development of asthma.

Gentile: What can we do in daily practice to help with this problem? Is it talking to school kids? Is it educating families when they come in? What can we do to make a dent in this problem and start to make an impact?

Myers: I think first and foremost is to get resources to pediatricians and family care practitioners in ambulatory clinic areas so that the message can be parlayed into prevention and maintenance and you can have more than 5 minutes to discuss medications and treatment plans, to make sure that you're doing things the right way. The second component is really moving towards evidence-based medicine and practice in the hospital and the ED, because I think there's a lot of unnecessary care out there, because it's ordered and given, as opposed to ordered and needed. Protocols and evidence-based medicine in the ED and acute-care settings is a must. Regarding asthma educational endeavors, we need interventions that really promote adherence and patient selfassessment, access to treatment plans, and the ability to take charge of their own disease.

Walsh: Do you believe that Atrovent helps prevent hospital admissions?

Myers: I think if you looked at the evidence-based scoring in the 2007 guidelines, ${ }^{1}$ it is grade A evidence that states that use back-to-back combinations of albuterol and ipratropium in the ED have a much better return to normal pulmonary function status and lower admission rate. Without a doubt it's good solid evidence in patients with moderate to severe exacerbations. In patients with relatively mild or quasi-moderate exacerbations it probably doesn't have as big of a benefit. In Qureshi's paper ${ }^{2}$ in the New England Journal of Medicine, it was the patient with severe air-flow obstruction and severe exacerbation that responded best. That's been duplicated. On the flip-side, there is also highlevel evidence that continuing on after the severe exacerbation and decrease in pulmonary function in the in-patient setting is of no benefit in a hospitalized patient outside of the ICU.

1. National Asthma Education and Prevention Program. Expert Panel Report 3 (EPR-3): Guidelines for the diagnosis and management of asthma-summary report 2007. J Allergy Clin Immunol 2007;120(5 Suppl): S94-S138.

2. Qureshi F, Pestian J, Davis P, Zaritsky A. Effect of nebulized ipratropium on the hospitalization rates of children with asthma. N Engl J Med 1998;339(15):1030-1035.

Walsh: We currently switch in-patients over to MDI, usually at 3 or 4 times a day, but Atrovent has kind of thrown a wrench in it, because some people are saying why don't we start them on MDI in the ED and start the education? Then we could either send them home with that or keep them on the same thing in the hospital and reinforce the education, rather than waiting until discharge and trying to hammer in education without a lot of reproducibility.

Myers: It's a tough question that hasn't been fully answered. I think from the standpoint of patient adherence to therapy and to validate the patient's ability to deliver the medications appropriately, the sooner you can get started, the sooner you can reinforce it to promote adherence. The meta-analyses indicate there is no difference between MDI with VHC and nebulized $\beta$ agonists. ${ }^{1}$ It comes down to patient preference and institutional preference, which is probably more resource-related than treatment-related. In the pediatric population we've seen a gradual shift toward MDI with VHC, so we can teach patients that MDI works just as well as nebulizer and we can watch their technique to make sure it's effective. The sooner you get it started in the in-patient setting, the better for everybody.

1. Dolovich MB, Ahrens RC, Hess DR, Anderson P, Dhand R, Rau JL, et al; American College of Chest Physicians; American College of Asthma, Allergy, and Immunology. Device selection and outcomes of aerosol therapy: evidence-based guidelines. Chest 2005;127(1):335-371.

Cheifetz: Tim, I want to ask you to focus on a hot topic in pediatric critical care: aminophylline. A recent international survey about aminophylline became a generational debate. The more senior physicians are generally quick to move to aminophylline in the ICU setting for patients who are refractory to the first-line therapies: $\beta$ agonists, corticosteroids, and possibly heliox. Younger physicians seem to be more resistant to aminophylline, for fear of toxicity. Having used aminophylline for years, I've found that if I dose it appropriately and follow the levels closely, I've had great success and little toxicity. What is your view on aminophylline? Is it a therapy we should consider as second-line, or does the toxicity risk outweigh the benefit?

Myers: Ira, I think it's a tool in the toolbox. But you're right that there has been a gradual shift to go with less toxic agents. A lot of patients have the need for systemic corticosteroids, so it's an area that had some research a few decades ago, but probably not enough scientific study to really determine if there is a true benefit over 
risk for aminophylline in most aspects of critical care medicine. If you're in a controlled setting with the ability to monitor, you can minimize the risks. Most of the risks and detriments about aminophylline are in the ambulatory out-patient setting, because of dosing regimen and having to bring the patient back and do serial monitoring, which doesn't apply in the ICU.

Rubin: Regarding your comment on aerosol delivery for asthma: we have used only MDI with VHC for the last 15 years, including in the ICU, and it has not been an issue at all. Many places have switched to MDI, and it certainly makes it easier to teach, easier to evaluate, easier to assess, and there are fewer systemic adverse effects because of system absorption.

Willson: Would you comment on magnesium?

Myers: The meta-analysis by Rowe and Camargo ${ }^{1}$ looked at magnesium in the ED and ICU setting, in patients with moderate to severe exacerbation, and magnesium definitely had a benefit and quicker resolution of the exacerbation. In patients with mild to slightly moderate exacerbations there was little to no benefit, in pediatric or adult patients. There's still not a lot of research. A paper by Schuh was just published, ${ }^{2}$ but I haven't read it yet. Magnesium is another tool in the toolbox for patients who aren't responding to $\beta$ agonists and systemic corticosteroids. When you get to that point, you want to pull out everything you have in the toolbox to try to avoid intubating, because it becomes a mess when you have to intubate down into an obstructed asthmatic airway.
1. Rowe BH, Camargo CA Jr. The role of magnesium sulfate in the acute and chronic management of asthma. Curr Opin Pulm Med 2009;14(1):70-76.

2. Schuh S, Macias C, Freedman SB, Plint AC, Zorc JJ, Bajaj L, et al. North American practice patterns of intravenous magnesium therapy in severe acute asthma in children. Acad Emerg Med 2010;17(11):1189-1196.

Willson: Have you personally ever seen it work?

Myers: We have used it, but it's anecdotal. I want to stay away from anecdotal medicine and focus on the literature and the evidence. There are evidence-based collaboration studies that say, yes, it does work in moderate to severe exacerbations, but most of those studies have been in adults. Anecdotally, we've used it in kids and I've seen it work.

Brown: I've given magnesium to many kids, but we've also given them so many other things, how do you know if it was the magnesium that worked? That's always a difficulty, because we've thrown everything at them by that point. What's your opinion on the benefit of levalbuterol?

Myers: It was a frequently mentioned player 5 or 6 years ago. We did probably one of the largest ED trials: a double-blind randomized controlled trial that compared levalbuterol to regular albuterol, and it did seem to decrease our hospital admission rate. ${ }^{1}$ There were a couple studies with slightly smaller patient populations, and maybe a different genetic population, than what we typically see in Ohio, that didn't find benefit. 2,3 Certain patients may respond better, from a phenotypic standpoint. We need much more research into phenotypes and severity and how they respond to different medications and different treatment. It's largely fallen off the radar because of cost, so we don't see it as much now.

1. Carl JC, Myers TR, Kirchner HL, Kercsmar CM. Comparison of racemic albuterol and levalbuterol for treatment of acute asthma. J Pediatr 2003;143(6):731-736.

2. Hardasmalani MD, DeBari V, Bithoney WG, Gold N. Levalbuterol versus racemic albuterol in the treatment of acute exacerbation of asthma in children. Pediatr Emerg Care 2005;21(7):415-419.

3. Qureshi F, Zaritsky A, Welch C, Meadows T, Burke BL. Clinical efficacy of racemic albuterol versus levalbuterol for the treatment of acute pediatric asthma. Ann Emerg Med 2005;46(1):29-36.

Brown: I remember that study caught my attention, because what I saw on my end was that everybody was ordering levalbuterol because they could. And I still see that now in the neonatal ICU: a lot of the time it's all levalbuterol.

Walsh: When you give an MDI with albuterol and Atrovent in the ED, do you throw away the CombiVent after the first 3 doses? Do you reorder? Do you separate albuterol and Atrovent? Do you throw the Atrovent away when they're admitted?

Rubin: We have been using the CombiVent inhaler initially and were giving it to the parents afterwards. For a while we were permitted to reuse them by using the appropriate VHC, but it was still expensive. I don't know what the current practice is in the ED, but in the hospital we're not using the combination at this point, but they go home with their MDIs and a prescription. For those who are seen in the ED it's only the more severe ones who are placed on the CombiVent. 